\title{
Interlaminar and Lateral Excitatory Amino Acid Connections in the Striate Cortex of Monkey
}

\author{
Zoltan F. Kisvarday, ${ }^{1-3}$ Alan Cowey, ${ }^{3}$ A. David Smith, ${ }^{2}$ and Peter Somogyi ${ }^{1,2}$ \\ 11st Department of Anatomy, Semmelweis University Medical School, H-1450 Budapest IX, Hungary, ${ }^{2 M R C}$ Anatomical \\ Neuropharmacology Unit, University Department of Pharmacology, Oxford OX13QT, United Kingdom, and 'University \\ Department of Experimental Psychology, Oxford, United Kingdom
}

The intrinsic excitatory amino acid pathways within the striate cortex of monkeys were studied by autoradiographic detection of retrogradely labeled somata following microinjections of $\mathrm{D}-{ }^{3} \mathrm{H}$-aspartate ( $\mathrm{D}-{ }^{3} \mathrm{H}-\mathrm{Asp}$ ) into different layers. The labeled amino acid was selectively accumulated by subpopulations of neurons and, to a small extent, by glial cells, the latter mainly in the supragranular layers. Immunocytochemical detection of neurons containing GABA showed that, apart from a few cells exclusively in layer I, GABAergic neurons do not accumulate $\mathrm{D}-{ }^{3} \mathrm{H}-\mathrm{Asp}$.

Several lines of evidence suggest that $\mathrm{D}-{ }^{3} \mathrm{H}-\mathrm{Asp}$ uptake occurred only at nerve terminals; thus, the pattern of perikaryal labeling allowed the delineation of interlaminar and lateral projections. Neurons in layer I probably project laterally, and layer I receives wide-ranging projections from layer IVB and layer $V$ from cells up to $1300 \mu \mathrm{m}$ laterally. Some neurons in layer II send a focused projection to lower layer VI. Some neurons in layers II/III project up to $1 \mathrm{~mm}$ laterally within their own layer, but relatively few neurons can be labeled in these projections. Similarly, in layers II/III few neurons can be retrogradely labeled from layers $V$ and upper VI, and this projection is organized such that cells closer to the pia project deeper in layer V/VI. The connections of layer IVA could not be revealed separately because of the difficulty of confining injections to this thin sublamina. Neurons in layer IVB project up to $1300 \mu \mathrm{m}$ within IVB itself. A small number of cells from IVB also project to layers III, IVC-alpha, V, and VI with much more restricted lateral spread. Neurons in upper IVC-alpha send axons to layer IVB with at least 600-800 $\mu \mathrm{m}$ lateral spread. Neurons in lower IVC-alpha/ upper IVC-beta project to layer III with at least 300-500 $\mu \mathrm{m}$ lateral spread. The bottom 50-80 $\mu \mathrm{m}$ of layer IVC-beta contains neurons with a very focused projection, apparently exclusively to the layer III/IVA border region. Both layers IVC alpha and beta have rich connections within themselves, the beta sublayer having more restricted lateral connections. Some neurons in layer IVC-beta give a laterally restricted small input to layers IVC-alpha and IVB. Both IVC-alpha and

\footnotetext{
Received Apr. 14, 1988; revised July 6, 1988; accepted July 20, 1988.

We are grateful to Mrs. Klara Boczko, Miss Dimitra Beroukas, and Mr. Frank Kennedy for excellent technical assistance, and to Mrs. Dorothy Rhodes for secretarial assistance.

Correspondence should be addressed to P. Somogyi, MRC Anatomical Neuropharmacology Unit, University Department of Pharmacology, South Parks Road, Oxford OX1 3QT, U.K.

Copyright (C) 1989 Society for Neuroscience $0270-6474 / 89 / 020667-16 \$ 02.00 / 0$
}

-beta project to layers $\mathrm{V}$ and $\mathrm{VI}$, and these projections are spread at least $400 \mu \mathrm{m}$ laterally. Neurons in layer $V$ project to all layers, but the projection to layers I-III and within layer $\checkmark$ itself spread much further laterally than the projections to layers IV and VI. The projection to layer VI is largely from the lower part of layer $V$, while to the superficial layers it is mainly from upper layer $V$. Some neurons in layer $V I$ project to layers III-V, as well as within VI itself, the latter having the widest lateral extent, up to $1 \mathrm{~mm}$. Probably different populations of cells are involved in these pathways.

The selective uptake and transport of $\mathrm{D}-{ }^{3} \mathrm{H}-\mathrm{Asp}$ is an informative method for the study of local cortical pathways. In addition to pyramidal cells long suspected of using excitatory amino acids as transmitters, spiny stellate and layer $\checkmark$ neurons with exclusively intracortical axons also selectively accumulate $\mathrm{D}-{ }^{3} \mathrm{H}-\mathrm{Asp}$ and probably use excitatory amino acids as transmitters. The comparison of pathways revealed by $\mathrm{D}-{ }^{3} \mathrm{H}-\mathrm{Asp}$ with known or suspected GABAergic pathways in many cases suggests a parallel organization of putative excitatory and inhibitory intrinsic connections.

The orderliness of cortical connections is most apparent in the striate cortex of primates. Here, the cortical laminae are sharply delineated and the terminal processes of many of the afferents and of the local neurons are precisely arranged with respect to these boundaries (Hubel and Wiesel, 1972; Hendrickson et al., 1978; Blasdel and Lund, 1983). The physiological properties of the neurons reflect the precise laminar pattern of connections (Hubel and Wiesel, 1968, 1972, 1977; Dow, 1974; Bullier and Henry, 1980; Blasdel and Fitzpatrick, 1984). The organization is also highly regular in the lateral dimension as detected by either the response properties of neurons (Blasdel and Fitzpatrick, 1984; Livingstonc and Hubcl 1984a) or by histochemical markers (for review, see Hendrickson, 1985).

The intrinsic connections of striate neurons have been delineated either by visualizing the processes of single cells (Ramon y Cajal, 1899, 1911; Valverde, 1971; Lund, 1973; 1984; Szentagothai, 1973, 1975; Lund and Boothe, 1975) or by using bulk labeling of populations of cells with HRP (Rockland and Lund, 1983; Livingstone and Hubel, 1984b; Blasdel et al., 1985; Fitzpatrick et al., 1985). The first method has the advantage of great accuracy but suffers from sampling problems; the second method is more representative but is complicated by the labeling of fibers of passage. Neither method gives any information on the neurochemical characteristics of the labeled cells.

Different types of visual information, e.g., concerning wave- 
length or achromatic contrast, arrive at different sublayers of layer IVC and are then transmitted to the other layers by axons of intracortical neurons. Some of the interlaminar connections probably use the inhibitory neurotransmitter GABA (Somogyi et al., 1983; Kisvarday et al., 1986a; Lund, 1987). But excitatory pathways must also be present since cortical cells have low spontaneous activity and the thalamic input restricted to layer IVC also activates cells in the other layers (Hubel and Wiesel, 1968, 1977; Dow, 1974; Mitzdorf and Singer, 1978; Bullier and Henry, 1980). The transmitter(s) of these facilitatory connections are not yet known.

Excitatory amino acids, such as glutamate and aspartate, are thought to be major neurotransmitters in certain classes of cortical neurons. A large body of physiological, pharmacological and biochemical evidence (Krnjevic and Phillis, 1963; Curtis et al., 1972; Hicks and Guedes, 1983; Fonnum, 1984; Ottersen and Storm-Mathisen, 1984h; Streit, 1984; Hicks et al., 1985; Tsumoto et al., 1986) indicates that glutamate and possibly other acidic amino acids are the transmitters of corticofugal pathways. Since most of these corticofugal projection neurons are pyramidal cells that also have extensive recurrent local axon collaterals within the cortex (Ramon y Cajal, 1911; Lorente de No, 1949; Szentagothai, 1973), it is very likely that the same transmitters are used at intracortical synapses. Nothing is known about the transmitters of the large number of presumed excitatory neurons that do not have axons leaving the area where the somata are located. One major class of presumed excitatory neuron with intracortical axons consists of spiny stellate cells, which are located in the middle, thalamocortical-recipient zone of primary sensory areas (for review, see Lund, 1984). In addition there are several classes of pyramidal cells with exclusively local axonal systems (Ramon y Cajal, 1911; Valverde, 1971; Lund, 1973; Gilbert and Wiesel, 1983). These major cell classes differ not only in their laminar position but also in their afferent and efferent synaptic connections. Therefore, their cytochemical and biochemical characteristics should be delineated in relation to their connections.

Immunocytochemistry is usually the preferred method for the localization of neurotransmitter markers to a particular population of neurons. Antibodies have been raised to glutamate and aspartate, and there are reports of their localization in the somata of cortical neurons, many of them pyramidal cells (StormMathisen et al., 1983; Ottersen and Storm-Mathisen, 1984a, b; Campistron et al., 1986; Aoki et al., 1987; Conti et al., 1987; Madl et al., 1987). However, the significance of the presence of acidic amino acids in the somata of neurons remains to be established, since all cells have amino acids in their cell bodies as part of the metabolic pool (for review, see Berl and Clarke, 1983; Nicklas, 1986). Thus, it is not surprising that, for example, the cholinergic motoneurons are also strongly immunoreactive for glutamate (Ottersen and Storm-Mathisen, 1984a, b) or that the highest aspartate concentration is localized in GABA-containing cells in the hippocampus and cerebellum (Ottersen and Storm-Mathiscn, 1985; Madl ct al., 1987).

The most informative and revealing method for determining the biochemical specificity of neurons that presumably use acidic amino acids as transmitters is the uptake of exogenously applied $\mathrm{D}^{-} \mathrm{H}$-Asp. There is support from biochemical and physiological studies that this metabolically inert amino acid is accumulated by the terminals of neurons whose probable transmitter is an acidic amino acid. The great advantage of this marker is that the labeled amino acid is retrogradely transported to the soma, delineating the projection areas of the chemically characterized cells (Cuenod et al., 1982; Cuenod and Streit, 1983; Ottersen and Storm-Mathisen, 1984b). The method has been used extensively for revealing long corticofugal pathways with presumed amino acid transmitters (Streit, 1980; Baughman and Gilbert, 1981; Rustioni and Cuenod, 1982; Matute and Streit, 1985; Manzoni et al., 1986; Barbaresi et al., 1987; Christic et al., 1987).

The present study was undertaken to visualize the much shorter interlaminar and lateral connections that presumably serve as activating systems, using the axonal transport of $\mathrm{D}^{-3} \mathrm{H}-\mathrm{Asp}$. The selectivity of the marker was confirmed by combined GABA immunocytochemistry to reveal the putative inhibitory neurons. Some of the results have been published in abstract form (Kisvarday ct al., 1984).

\section{Materials and Methods}

Three adult cynomolgus monkeys (Macaca fascicularis) were used. For intracortical injection of $\mathrm{D}^{-}{ }^{3} \mathrm{H}$-Asp the same procedure was carried out as reported for labeling cortical cells by the uptake of ${ }^{3} \mathrm{H}-\mathrm{GABA}$ (Somogyi et al., 1983; Kisvarday et al., 1986a). Briefly, animals were sedated with ketamine $(10 \mathrm{mg} / \mathrm{kg}$, Ketalar, Parke-Davis) i.m., and deep anaesthesia was maintained by sodium pentobarbital (Intraval, May \& Baker) i.v. After exposing the dorsolateral visual cortex, ${ }^{-3}{ }^{3} \mathrm{H}-\mathrm{Asp}(0.9-1.04$ $\mathrm{mM}, 12.5-21 \mathrm{Ci} / \mathrm{mmol}$; Amersham) was injected in artificial CSF by pressure through a fine glass capillary (tip diameter, 30-50 $\mu \mathrm{m}$ ) at several sites in one or both hemispheres. The capillary was advanced $6-8 \mathrm{~mm}$ into the cortex at an angle of about $15^{\circ}-30^{\circ}$ to the pial surface, usually in parallel with the lunate sulcus. In this way, injections remained in the same layer over a few millimeters. As the capillary was withdrawn, $0.06-0.1 \mu$ lisotope was ejected at 0.5 or $1 \mathrm{~mm}$ steps, so each injection track received about $8-13 \mu \mathrm{Ci}$ of the isotope.

Animals were allowed to survive $40-70 \mathrm{~min}$. They were then perfused transcardially with Tyrode's solution followed by fixative containing $1 \%$ glutaraldehyde (TAAB) and $1-1.5 \%$ paraformaldehyde (TAAB) in $0.1 \mathrm{~m}$ phosphate buffer, $\mathrm{pH}$ 7.4. Some blocks of the injected area were then processed for Golgi impregnation (Somogyi et al., 1981b). This step was carried out to study the processes of cells, but the quality of the material did not allow us to gather information relevant to the present study. Golgi impregnation had no effect on the distribution of the radioactive label. The blocks were cut at $80 \mu \mathrm{m}$ on a Sorvall tissue chopper perpendicular to the injection track and the pial surface. The sections were osmium-treated, dehydrated, and mounted in resin (Durcupan ACM, Fluka) on slides. Sections of 6 injection tracks were selected and reembedded for cutting serial semithin sections $(0.5$ or $1 \mu \mathrm{m})$. Consecutive sections were mounted in separate series on gelatin-coated slides, so that the same cell could be studied either by autoradiography or by postembedding GABA immunocytochemistry (Kisvarday et al., 1986a).

Each injection track was sampled at several levels so that a representative picture could be obtained about the depth of the track, its laminar position along its mediolateral extent, and the distribution of the retrogradely labeled cells. Each pattern described below was observed in at least in 2 , but usually in 3-6, separate injections. To identify the origin of retrograde labeling for long tangential pathways, we were careful to select sections that represented a position where the injection track remained in the same lamina. Nevertheless, because the injection tracks traversed at least from layer I to the middle of layer III, and often through all layers, it was not possible to identify the origin of the labeling for any single cell. Conclusions were drawn on the basis of evaluating the changes in the distribution of populations of cells as the injection track changed position.

Autoradiography was carried out as described previously (Somogyi et al., 1981b, 1983). The slides were dipped in Ilford K 5 or K2 nuclear emulsion and stored at $4^{\circ} \mathrm{C}$. After exposure for $18-118 \mathrm{~d}$, sections were developed in Kodak D-19B developer, fixed, and lightly counterstained with a mixture of toluidine blue and Azur II. Neurons labeled for D- ${ }^{3} \mathrm{H}$-Asp were drawn from counterstained semithin sections using a drawing tube and $50 \times$ oil-immersion objective. Cells densely covered by silver grains were considered labeled. Cell bodies with fewer grains were compared with the neuropil or to neighboring cells and considered labeled if the grain density was at least 4 times higher than over the 


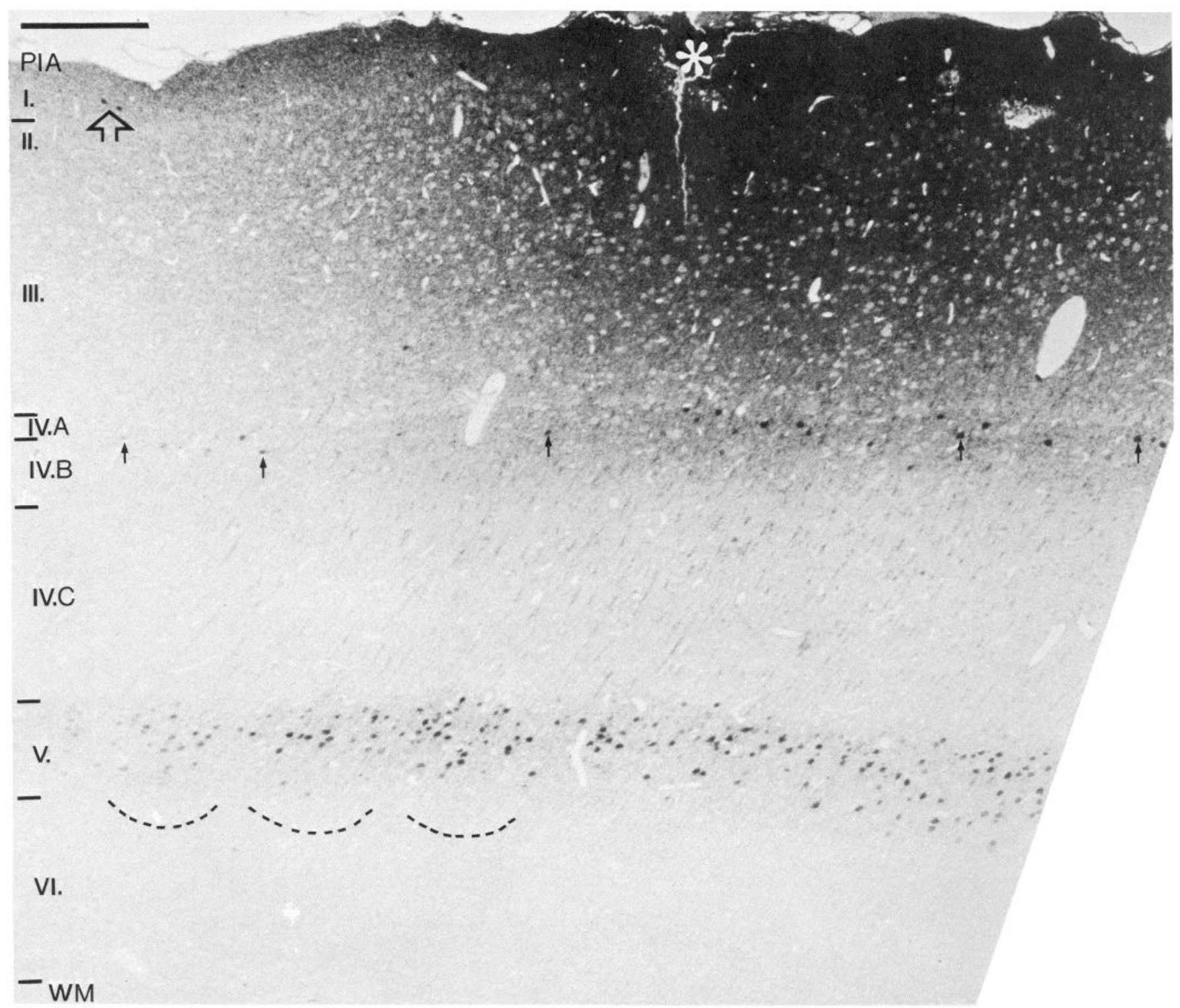

Figure 1. Light micrograph of a 1- $\mu \mathrm{m}$-thick section processed for autoradiography. Injection of $\mathrm{D}-{ }^{3} \mathrm{H}-\mathrm{Asp}$ into layers I and II. Long-range lateral retrograde labeling is seen in layers I (open arrow), IVB (arrows), and V. In addition to cell bodies, the neuropil is also labeled in the same layers. Neurons in layers IVB and V are clustered (broken lines). In all subsequent figures, the injection site (asterisk) and the white matter (wm) are indicated. Scale bar, $200 \mu \mathrm{m}$.

perikarya of at least 3 adjacent neurons, excluding densely labeled neurons, and over the neuropil.

The immunocytochemical demonstration of GABA was carried out using the unlabeled antibody peroxidase-antiperoxidase method (Sternberger et al., 1970) as reported earlier (Somogyi et al., 1985; Kisvarday et al., 1986a). The position of neurons reacting for GABA was drawn under $50 \times$ objective and superimposed on drawings of the same area from adjacent sections processed for autoradiography. This procedure revealed somata that were labeled by either or both techniques.

In addition to neuronal labeling some glial cells also accumulated D- ${ }^{3} \mathrm{H}$-Asp selectively. Glial cells were distinguished from neuronal somata on the basis of light and electron microscopic features. In counterstained sections, glial cells accumulating $\mathrm{D}^{-}{ }^{3} \mathrm{H}-\mathrm{Asp}$ show darker cytoplasm and nucleus than neurons. They are closely associated with either the wall of blood capillaries or with neuronal somata.

Layering of the cortex followed the scheme of Lund and Boothe (1975).

\section{Results}

The area covered by silver grains around the injection track represents label in the neuropil, most of it probably in nerve terminals. This area where the concentration of aspartate is highest at the center is almost certainly larger than the zone in which uptake will result in detectable labeling in the somata of cells. It is expected that the effective uptake zone will differ for each neuronal class because of the differences in the density of their nerve terminals. Neurons with a high density of terminals at the center of the injection site and with few boutons elsewhere are more likely to be labeled than cells with low bouton densities.

The effective area of uptake can be shown to be a very narrow cylinder along the injection track. A displacement of as little as 

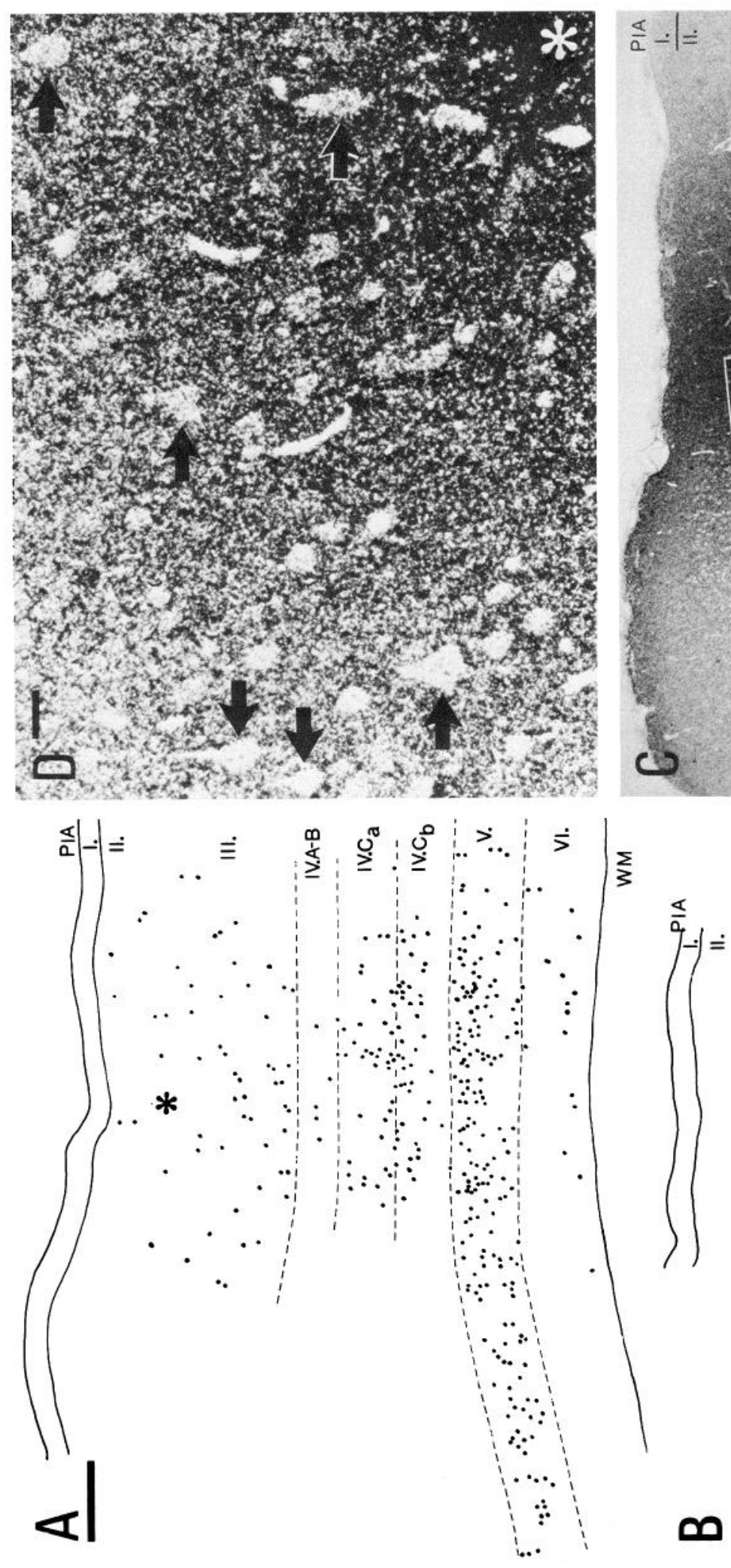
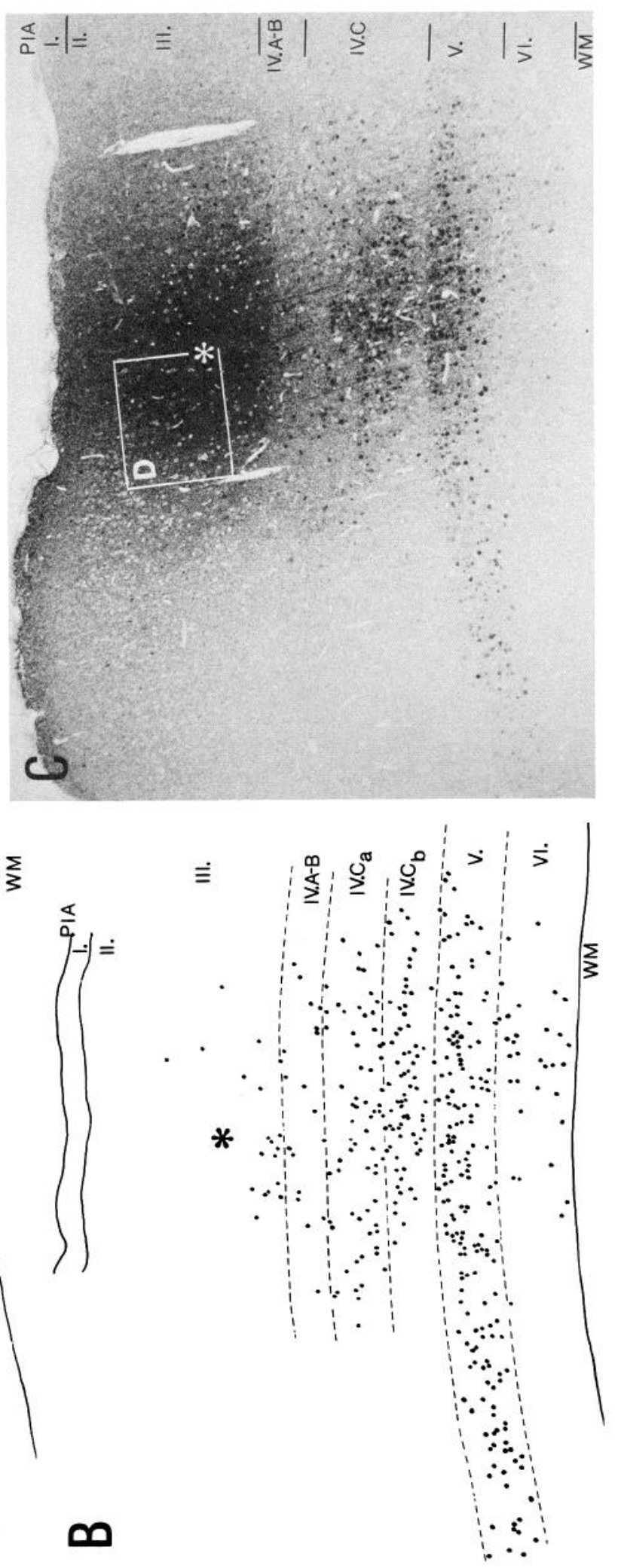

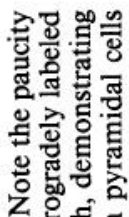

Z 연뎐

닌

政

ठृ

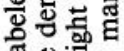
๘

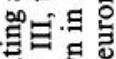

它政

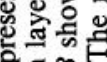
른.

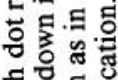
둥. 记 颉 ㄴ․ㄹ हैं क.

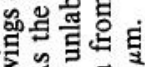

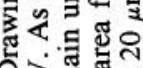
क 杀> E 正昰 면 目贾

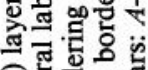
0 记

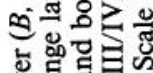

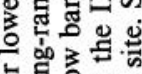
흐응ㅎㅄ 호

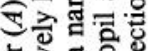
政 원 응 온 क्षे र्र 보의 是已严 원.

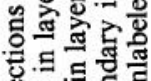

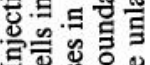
छ屯. ن 


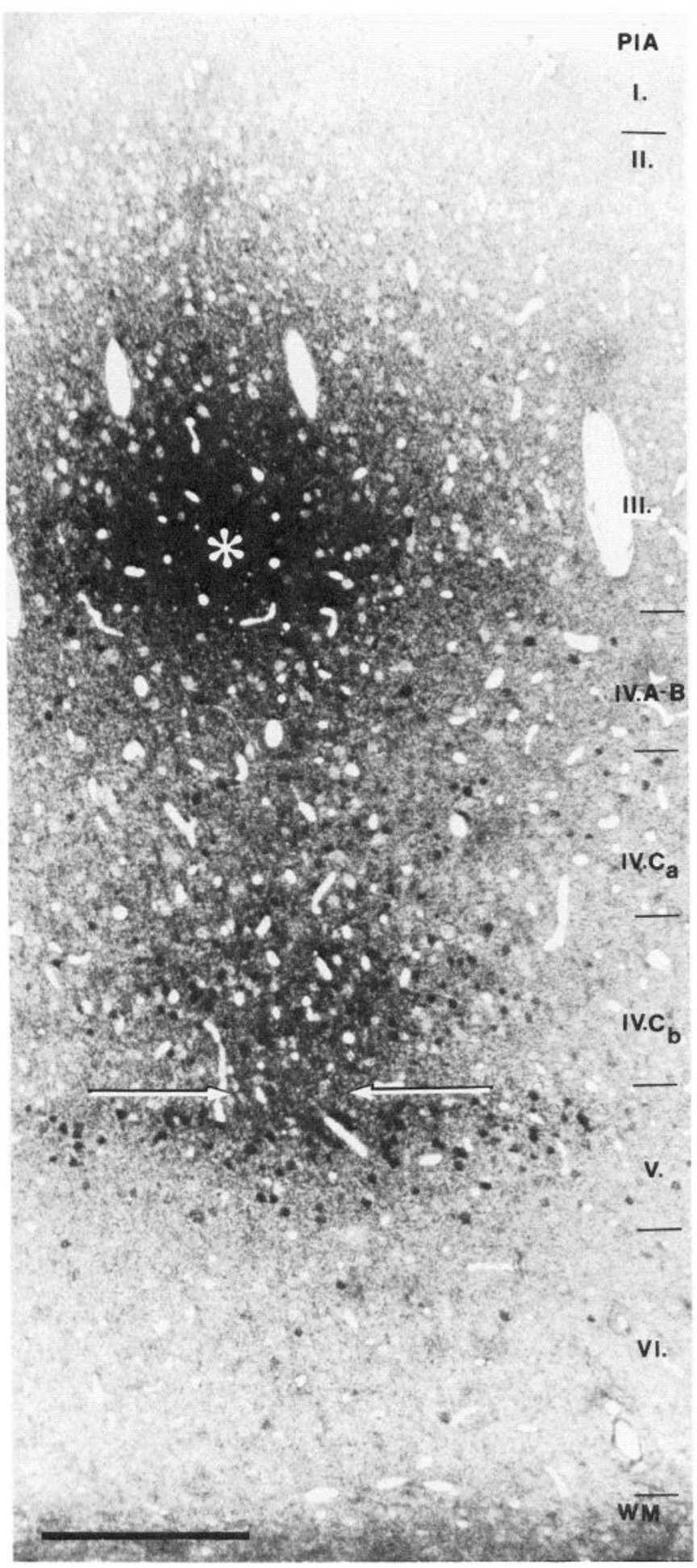

Figure 3. Small injection of $\mathrm{D}-{ }^{-3} \mathrm{H}$-Asp into the border region of layers III/IVA. The retrogradely labeled cells densely fill IVC, mainly the beta sublayer. Note the narrow band of labeled somata and neuropil in the lowermost part of IVC-beta (arrows). The labeling of layer V is intense, and there are also a few cells in layer VI. Scale bar, $200 \mu \mathrm{m}$.

$50-100 \mu \mathrm{m}$ in the radial position of the track resulted in a clear shift in the proportions of certain labeled cell populations in the different laminae. On the other hand, for some populations of neurons a radial displacement of several hundred microns made no difference to the labeling, indicating that these cells have widespread axonal arborization.

In preliminary experiments it was found that with small injections of $\mathrm{D}^{-}{ }^{3} \mathrm{H}$-Asp, labeled cells were present well beyond the area that was diffusely labeled throughout the neuropil. The anisotropic distribution of the cells indicated that they were labeled by retrograde axonal transport. This assumption will be used throughout in the description of the results. The results will be presented in an order that follows the injection site from the pia towards the white matter.

Injections in layers $I / I I$. Layer I could not be injected in isolation because of its narrowness, and the isotope probably spread in every case to layer II (Fig. 1). Nevertheless, because of the unique pattern of retrograde labeling (i.e., not present after injection of layers II-III), most of the cells were probably labeled from layer I. There were 3 populations of labeled cells: in layers I, IVB, and V, and up to $1300 \mu \mathrm{m}$ laterally from the injection site (Fig. 1). By far the largest population was in layer $\mathrm{V}$, mainly in its upper half. The cells in layers IV and V seemed to be clustered. The neuropil was also labeled in these layers. Layers II and III closest to the injection site contained only a few labeled neurons.

Injections in layers $I I / I I I$. Scattered neurons appeared laterally in layers II and III up to $1000 \mu \mathrm{m}$ from the track, but only a small proportion of neurons was labeled in these layers, even immediately next to the injection track (Fig. $2 D$ ). In layer IVA/B neurons were labeled only radially from the injection site; the wide lateral labeling observed after layer I injections was greatly reduced as soon as the injection centered on layer III. The number and proportion of labeled neurons in layer IVC increased gradually as the injection moved away from the pia (Fig. 2). These small cells were located in both IVC-alpha and IVC-beta in a group, around $500-800 \mu \mathrm{m}$ wide. The pattern of labeling in layer V, namely, a broad band, was very similar, whatever the precise injection site in layers II and III. The proportion of labeled neurons gradually increased in layer VI radially from the injection site in a band about $600-800 \mu$ m wide (Fig. 2).

As the injection track reached the layer III/IVA border, labeled neurons appeared in the narrow band of IVC-beta immediately next to layer V (Fig. 3). Their lateral spread was usually less than $100 \mu \mathrm{m}$. Because of the thinness of layer IVA it could not be decided whether these cells were labeled from the lowermost part of layer III, from layer IVA, or both. However, it was clear that they have different projections from the cells in the rest of the layer IVC. The more widely spread group of cells present in both upper IVC-beta and in lower IVC-alpha was still present in the cases of III/IVA border injections, thus these neurons contribute to the projection to most of layer III.

The other notable change following injections to the IVA region was the appearance of widespread lateral labeling in layer VI up to $800 \mu \mathrm{m}$ from the projection line of the track.

Injections in layers IVB. Relatively widespread lateral labeling was observed in IVB itself, up to 1000-1200 $\mu \mathrm{m}$ lateral from the injection track (Fig. 4). The neurons seemed to be clustered in groups about $400 \mu \mathrm{m}$ apart, and the neuropil was also labeled. Upper IVC-alpha also contained labeled cells but with smaller lateral spread of up to $600-800 \mu \mathrm{m}$ from the injection track. Neurons in IVC-beta were distributed in a narrow column radial to the track, in contrast to their distribution after more superficial injections. The lateral spread of labeling in layer $\mathrm{V}$ was much smaller than following supragranular injections. The proportion of labeled cells radial to the track was increased in layer 

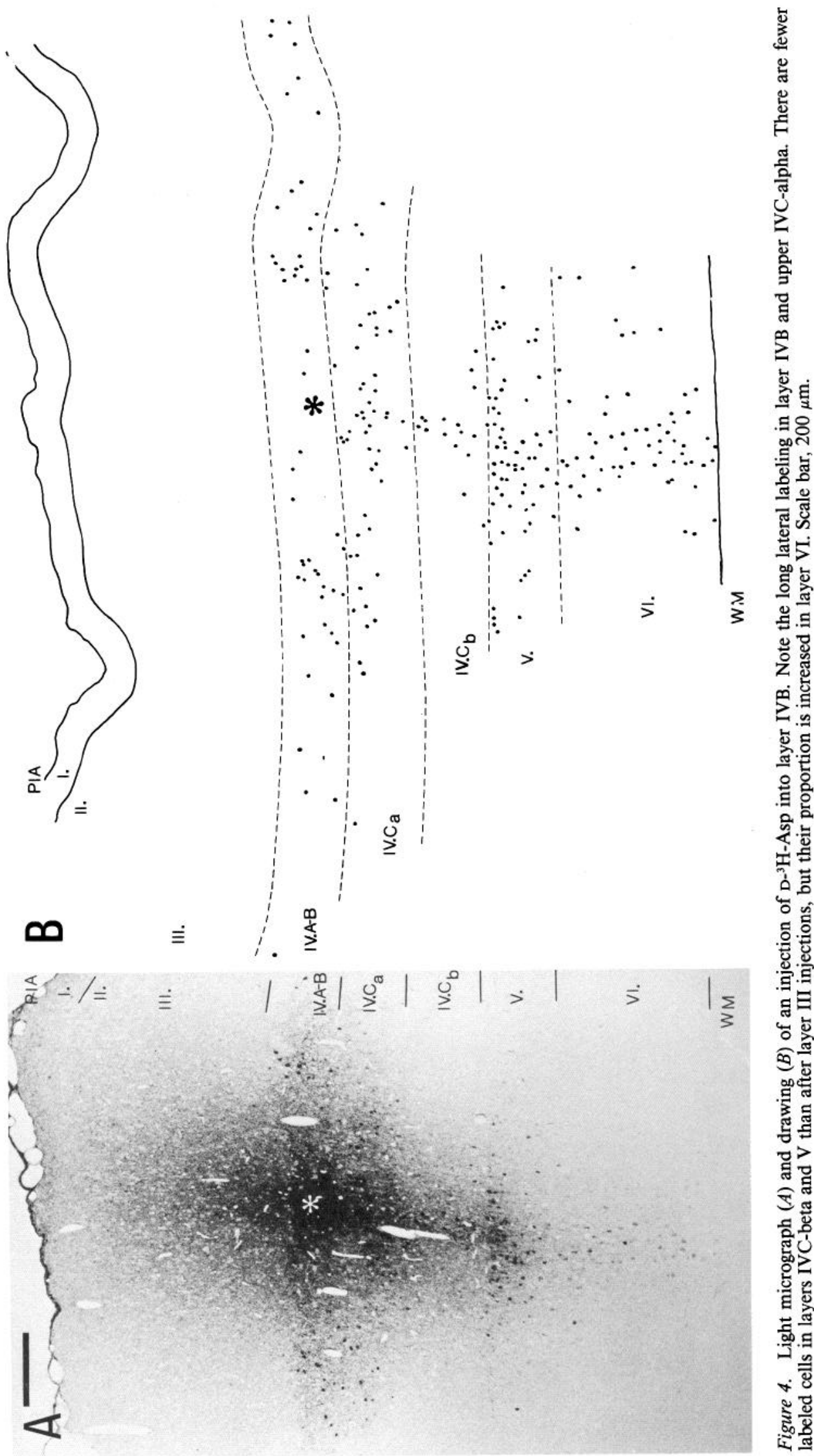

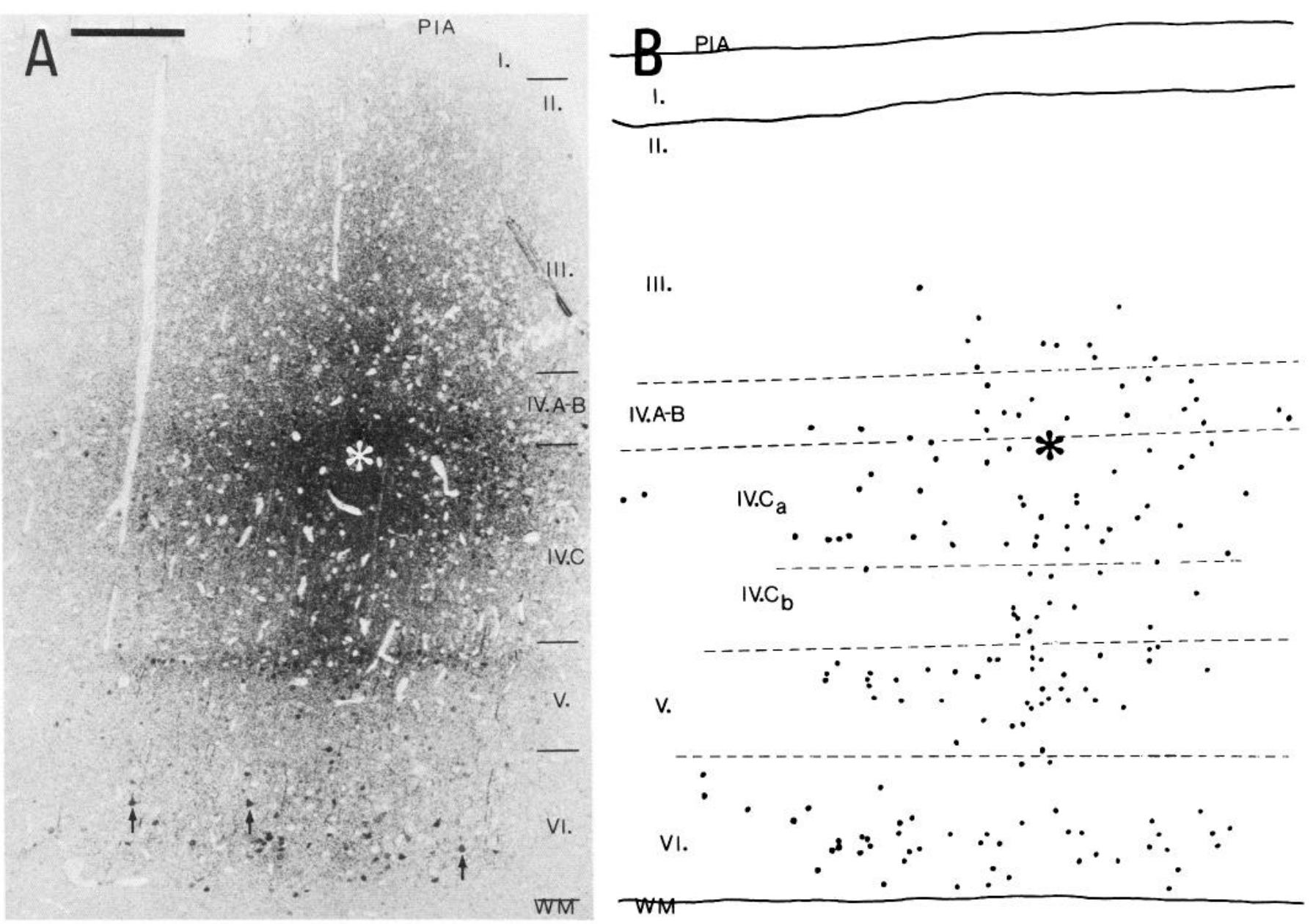

Figure 5. Light micrograph $(A)$ and drawing $(B)$ of injection of $\mathrm{D}^{-3} \mathrm{H}$-Asp into the border region of layers IVB/IVC-alpha. The proportion of retrogradely labeled cells is increased in layer VI and they are more widely distributed than with more superficial injections. Cells in IVC-beta are labeled only in a narrow band radially under the injection site. Note more widespread labeling in layer IVC-alpha and the lack of retrograde labeling in the supragranular layers. Scale bar, $200 \mu \mathrm{m}$.

VI, and the majority of retrogradely labeled cells were in a compact band about 200-300 $\mu$ m wide (Fig. 4).

Injection in layer IVC. As the injection track left layer IVB and entered IVC-alpha, the widespread lateral labeling disappeared in layer IVB; instead, labeled cells were distributed around the track (Fig. 5). The lateral spread of retrogradely labeled cells did not change in IVC. In the alpha sublayer, labeled neurons were present in the whole depth in contrast to the cases when only IVB was injected. The most notable change was in layer VI, where the lateral spread of labeled cells increased to up to $600 \mu \mathrm{m}$ from the radial projection of the track (Fig. 5). Injections at any depth of IVC-alpha produced the same pattern.

As the injection moved into layer IVC-beta the laterally labeled cells disappeared from IVC-alpha and neurons were only found immediately around the injection site, mainly in IVCbeta (Fig. $6 A$ ). Cells were also labeled in layer $\mathrm{V}$ but only close to the injection site and radial to it. Layer VI contained a distinct population of cells also radial to the injection site.

Injections in layer $V$. Sudden change was detected in the distribution of retrogradely labeled cells as the track crossed the IV/V border (Fig. 6, $B, C$ ). Labeled cells were present in layers $\mathrm{V}$ and upper VI up to $600 \mu \mathrm{m}$ from the injection site and reappeared in lower layer III, with a few cells in IVB. As the injection moved towards the white matter in layer $\mathrm{V}$, so the labeled cells in layer III moved towards the pia (Fig. $6 D$ ). The neuropil was strongly labeled in layer III, with a sharp border against layer IV and with gradually decreasing density towards the pia. Layer IVC showed similar labeling as after IVC injections.

Injections in layer VI. The most conspicuous retrograde labeling was in layer VI itself, up to $1200 \mu \mathrm{m}$ from the injection site laterally (Fig. 7). Layer V also contained neurons, spread less extensively, when the upper part of layer $\mathrm{V}$ was injected but contained hardly any labeled cells after deep layer VI injections. Layer IV had labeled cells throughout its depth with a distinct cluster centered on the IVC-alpha/beta border, where the neuropil was also strongly labeled. The lowermost part of IVC-beta was distinctly clear of label. Scattered cells were present throughout layer III. A small but conspicuous group of tightly packed cells appeared in layer II/upper III after injections bordering the white matter (Fig. 7C).

Intracortical projection patterns emerging from the transport of $D^{-3} \mathrm{H}$-Asp. From the analysis of the distribution of retrogradely labeled cells the connections can be summarized as originating from particular cell populations. This will be described also in an order descending from the pia.

Some neurons in layer I probably have long lateral connec- 


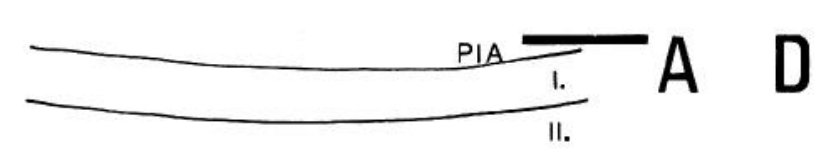

III.

IV.A-B

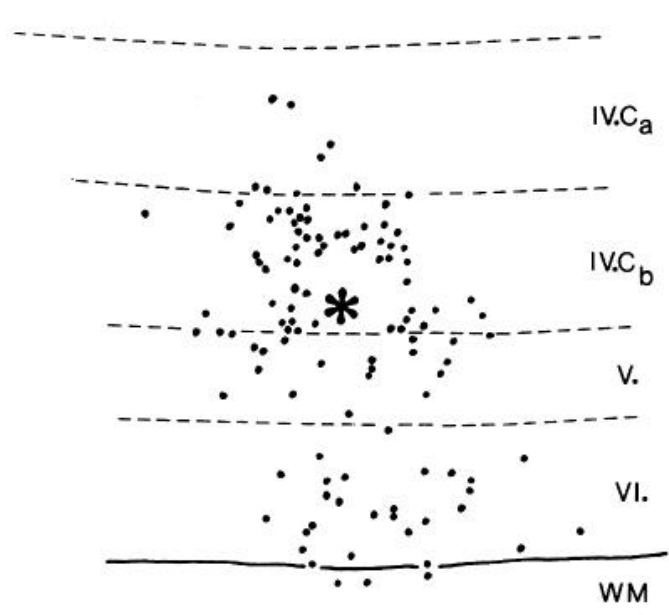

\section{B}
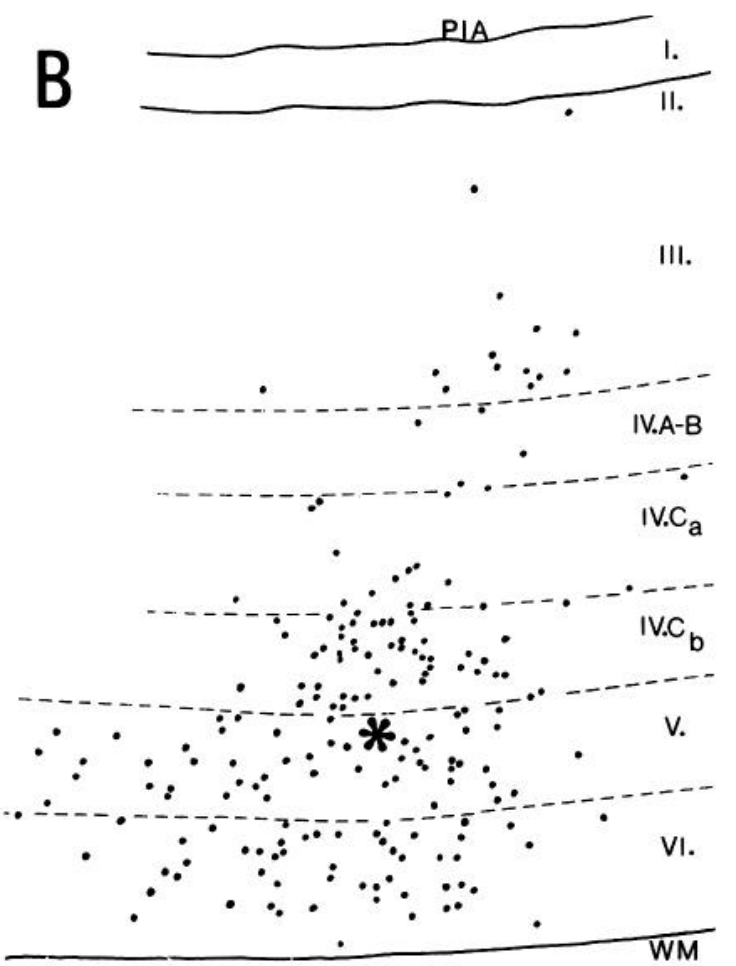

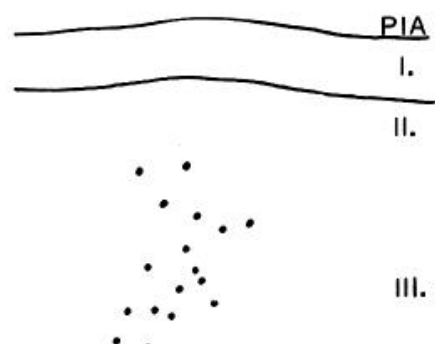

I.
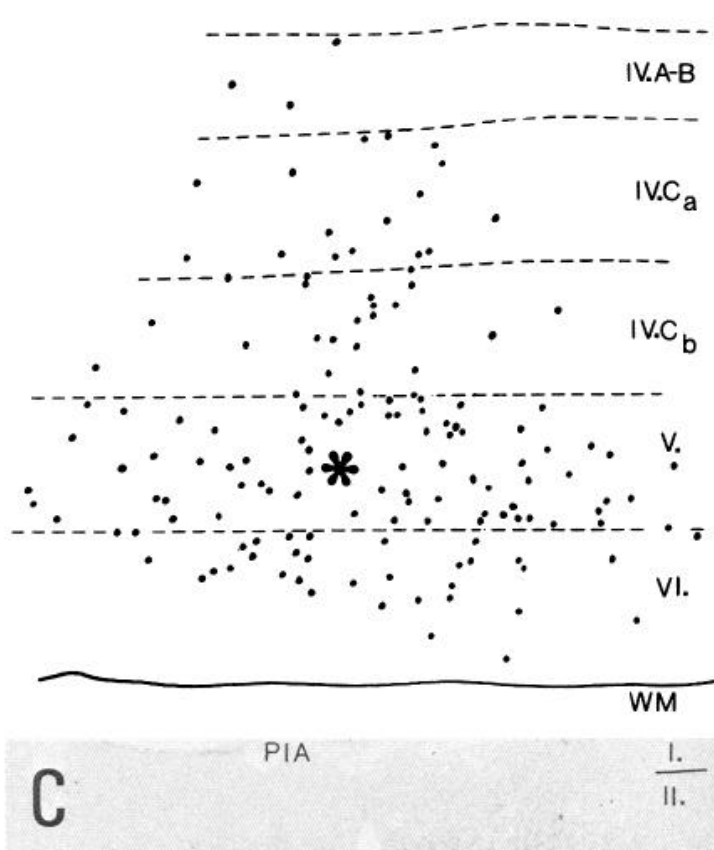

III.

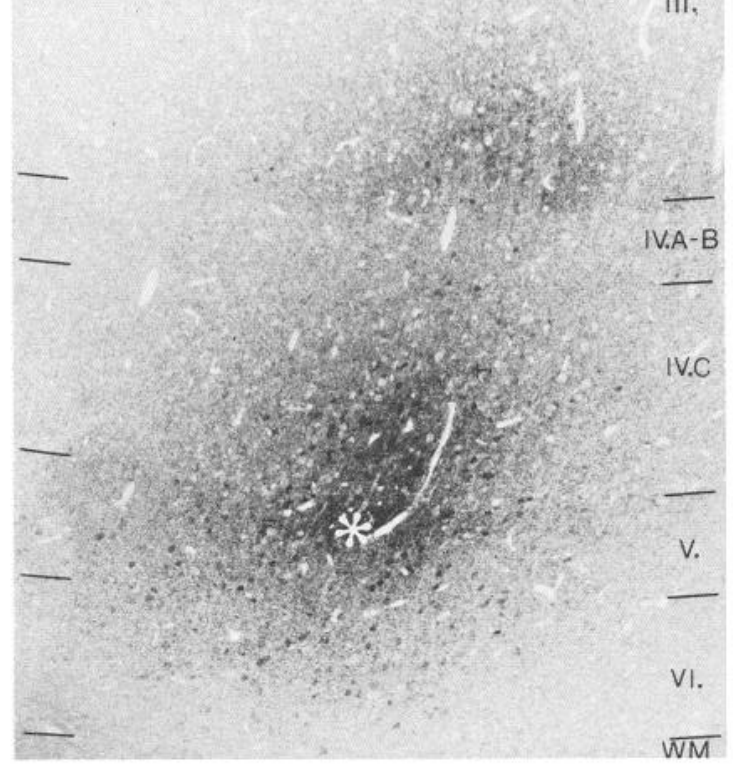

Figure 6. Light micrograph $(C)$ and drawings $(A, B, D)$ of injection of $\mathrm{D}-{ }^{-3} \mathrm{H}$-Asp into layers IVC-beta and V. $A$, Note the dense cluster of cells in IVC-beta around the injection site and another group radially towards the white matter in lower layer VI. $B$ and $C$, Drawing and light micrograph of the same section, demonstrating that, as the injection moves into layer V, a group of retrogradely labeled cells appears in lower layer III, together with labeling of the neuropil. $D$, Injecting lower $\mathrm{V}$ causes a shift in the position of the layer III cell group towards the pia. Note lateral connections in layer V. Scale bar (in $A$ ), $200 \mu \mathrm{m} ; A-C$ same magnification. 

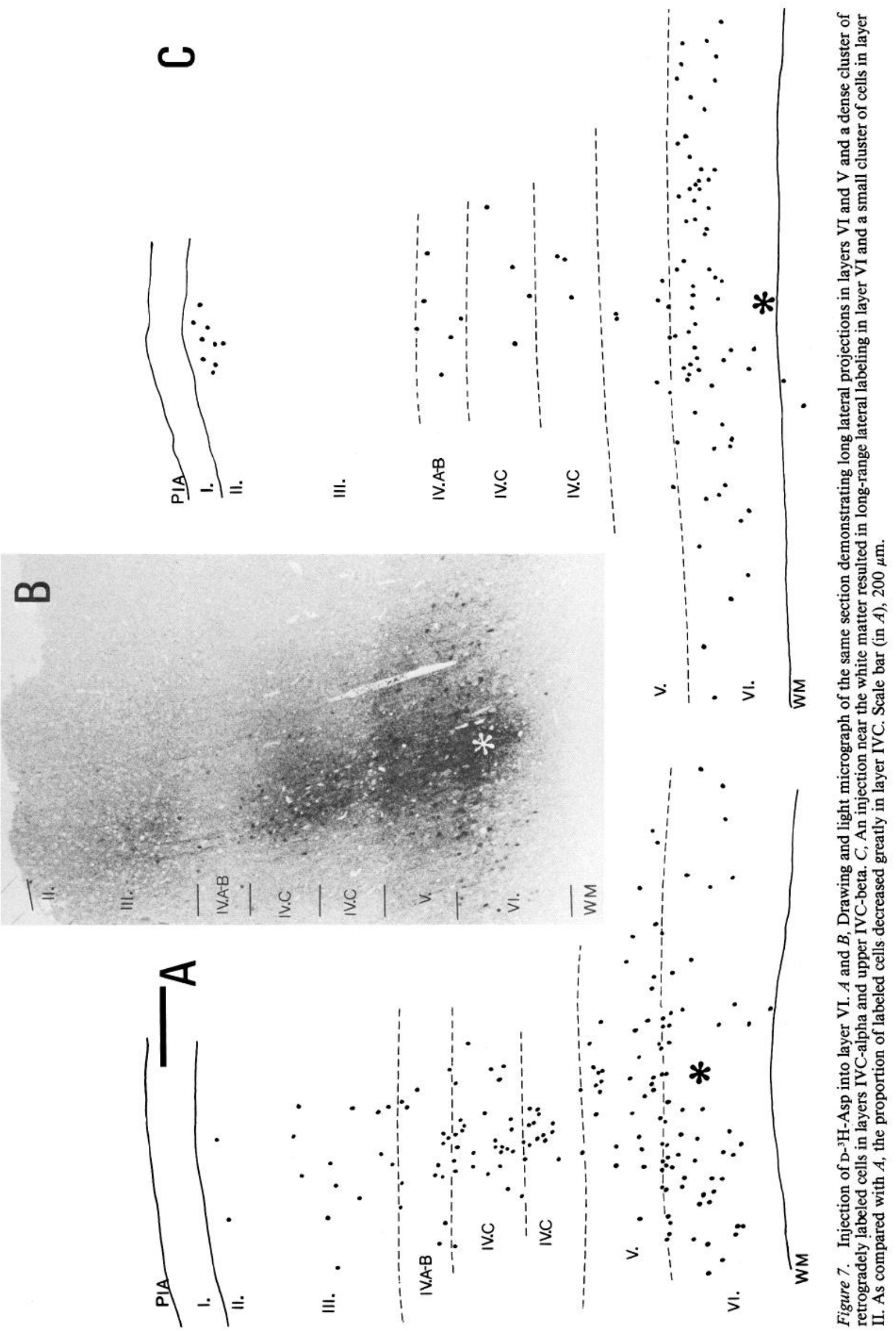

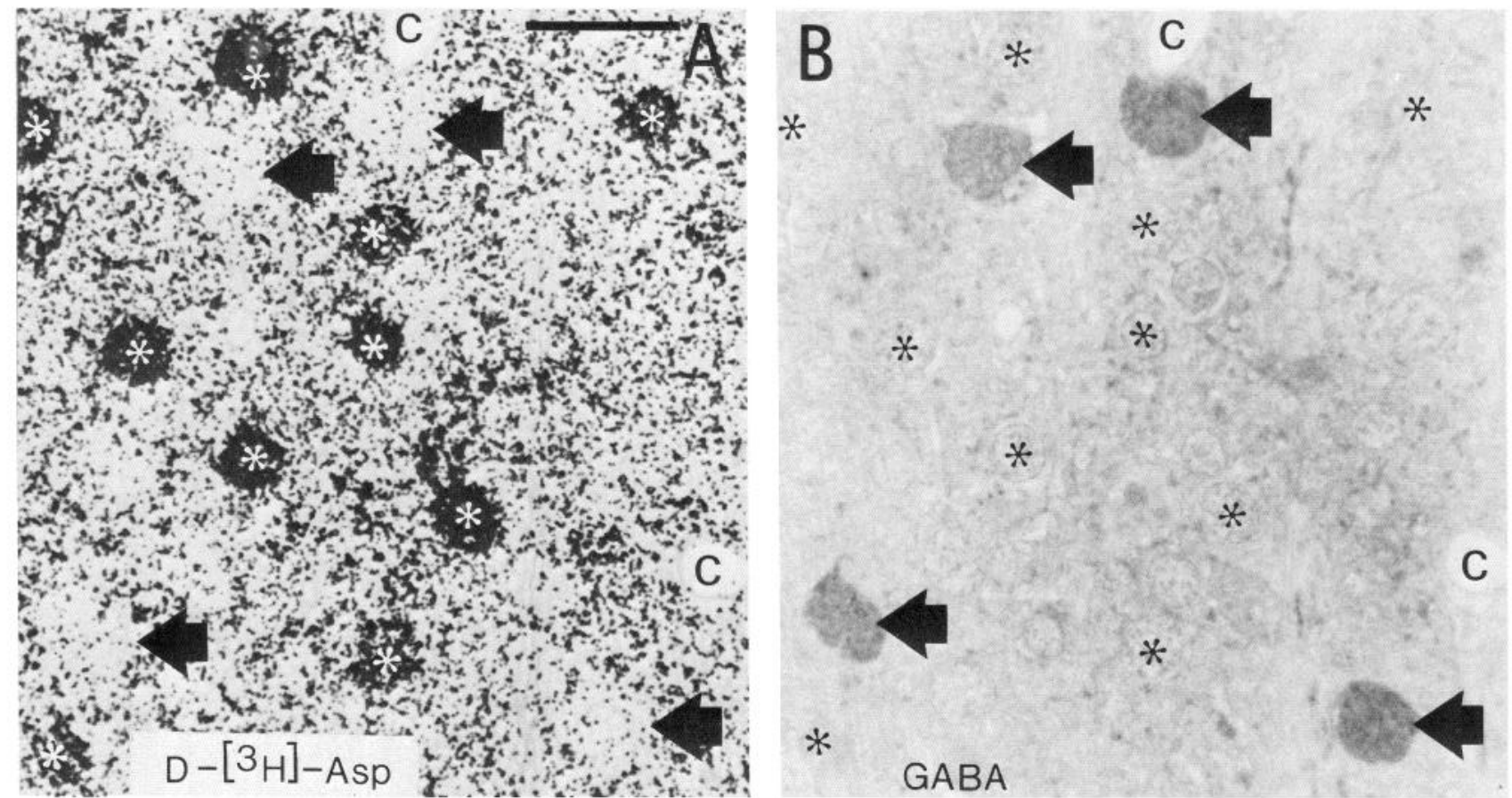

Figure 8. Adjacent $0.5-\mu$ m-thick sections of layer IVC-beta from an area that received an injection of D- ${ }^{3} \mathrm{H}$-Asp into lower layer III. Section $A$ was processed for autoradiography and $B$ for the immunocytochemical demonstration of GABA. Note that there is no overlap between the population of GABA-positive cells (arrows) and cells labeled by amino acid uptake (asterisks). c, capillaries. Scale bar, $20 \mu \mathrm{m}$.

tions within their own layer. However, because layer I is so thin, it is possible that some of the tracer injected at the top of the capillary track spilled over to the surrounding pia, in which case some layer I neurons may have accumulated the amino acid through their local terminals rather than through terminals at the injection site. Fortunately, this cannot be the only explanation for the labeling because labeled cells occurred in areas with very little neuropil labeling in layer I.

Some neurons in layer II have a tightly confined projection to lower layer VI, with little lateral spread. Neurons in layers II/III project laterally within their own layer up to $1000 \mu \mathrm{m}$, but their numbers are small. Similar numbers of cells project to layer V and upper VI, and this projection is organized such that cells closer to the pia project to deeper in layer V/VI. The connections of layer IVA could not be revealed separately because of its limited depth. Neurons in layer IVB project to layer I with relatively extensive lateral spread, similar to the projection within IVB itself. Small numbers of cells from IVB also project to layers III, IVC-alpha, V, and VI with much more restricted lateral spread. A substantial proportion of neurons, mainly in upper IVC-alpha, send axons to layer IVB with long lateral spread. Neurons in the layers of lower IVC-alpha/upper IVC-beta project to layer III with moderate lateral spread. The bottom $50-80 \mu \mathrm{m}$ of layer IVC-beta contains neurons with very restricted projection, directed apparently exclusively to the layer III/IVA border region. It is not possible to determine the exact laminar termination with our injections. In any case, because layer IVA is so thin, the identification of the target cells in this pathway would be more important than the designation of laminae. Both layers IVC-alpha and -beta have connections within themselves, the beta sublayer having shorter lateral connections. Some neurons in layer IVC-beta give a laterally restricted small input to layers IVC-alpha and IVB. Both IVC-alpha and -beta project to layers $\mathrm{V}$ and VI, and these projections show more extensive lateral spread. Neurons in layer V send a very widespread projection to layers I-III and are similarly connected within layer V. The projection to layer IV and VI is much more restricted both in its lateral spread and in the number of cells participating in it. The projection to layer VI is largely from the lower part of layer $\mathrm{V}$, whereas to the superficial layers it is mainly from upper layer V. Some neurons in layer VI project to layers III-V, as well as within VI itself, the latter having the widest lateral extent. Probably different populations of cells are involved in the pathways to the different laminae since the projections to IVC-alpha and V and within VI are widespread, while those to the other layers are restricted in their lateral extent.

Selectivity of $D^{-}{ }^{3} H$-Asp labeling. The results showed clear anisotropic distribution of labeled neurons. Similar patterns of selective labeling were reported following ${ }^{3} \mathrm{H}-\mathrm{GABA}$ injections into the striate cortex of monkey (Somogyi et al., 1981a, 1983; Kisvarday et al., 1986a). It was therefore important to see whether GABA-positive cells were among the neurons that accumulated $\mathrm{D}^{-}{ }^{3} \mathrm{H}-\mathrm{Asp}$, even though we already know that the 2 populations could not coincide perfectly because neurons accumulating ${ }^{3} \mathrm{H}$ GABA were nonpyramidal, whereas many neurons accumulating $\mathrm{D}^{-}{ }^{3} \mathrm{H}$-Asp were pyramidal. Several thousand $\mathrm{D}^{-}{ }^{3} \mathrm{H}-\mathrm{Asp}$ labeled cells from all layers close to the injection site, as well as in the most distant retrogradely labeled areas, were checked in the adjacent sections reacted immunocytochemically for GABA. In layer I about $50 \%$ of the neurons were both GABA positive and labeled by $\mathrm{D}^{-}{ }^{3} \mathrm{H}$-Asp. In the other layers, the 2 populations were completely different (Fig. 8).

Labeling of glial cells. Some of the labeled cells were only 5$7 \mu \mathrm{m}$ in their longest dimension and often lay in close proximity to pyramidal cells. These small cells were noted in layers II/III after injections into the same layers. In light microscopic, coun- 

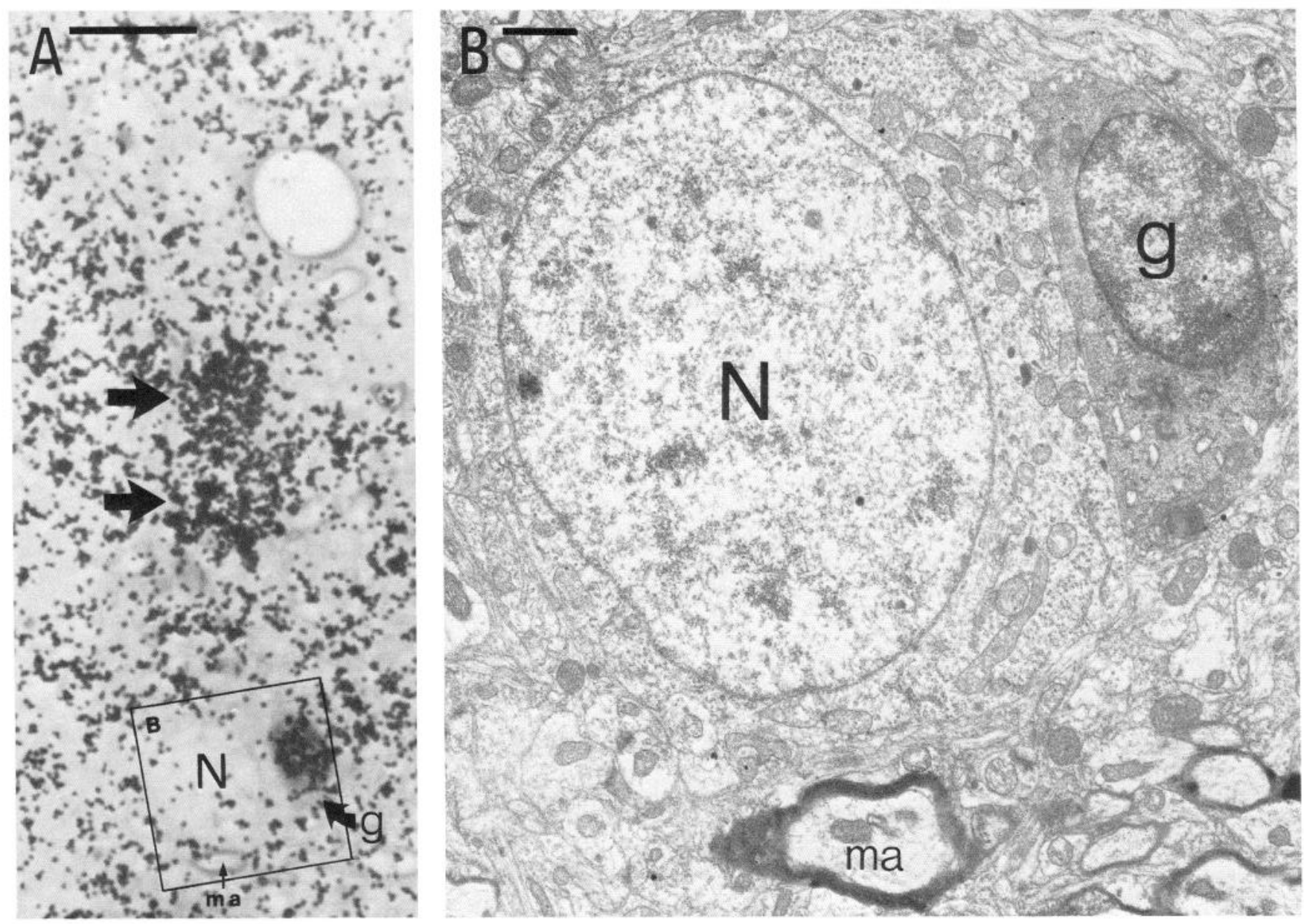

Figure 9. Light $(A)$ and electron $(B)$ micrographs demonstrating selective uptake of $\mathrm{D}-{ }^{3} \mathrm{H}-\mathrm{Asp}$ by glia. In $A, 2$ neurons (arrows) in layer III are labeled after injection of the tracer in the same layer. A third neuron $(N)$ is unlabeled, but an astroglial cell $(g)$ next to it is strongly labeled. The latter cells, together with a myelinated axon $(m a)$ as fiducial mark, are shown in $B$ for the identification of the glia. Scale bars: $A, 10 \mu \mathrm{m} ; B, 1 \mu \mathrm{m}$.

terstained sections they had the features of glial cells. This was proved by electron microscopic examination of cells that were first identified in semithin sections as selectively accumulating $\mathrm{D}^{-}{ }^{3} \mathrm{H}$-Asp (Fig. 9). This glial labeling did not distort our results because in semithin sections glial cells can be unequivocally recognized. Because the sections are so thin, the silver grains can be easily allocated to a particular cell even if 2 cells are immediately adjacent.

Lateral anisotropy in the connections. Some of the injections resulted in an asymmetrical lateral distribution of both the diffusely labeled neuropil and the retrogradely labeled cells relative to an imaginary line perpendicular to the pia and passing through the injection track. This was especially conspicuous with some of the more extensive lateral labeling. It is very likely that the projections are not radially symmetrical, but because we had no functionally defined landmarks such as ocular dominance columns or cytochrome oxidase puffs, the correspondence in the tangential direction between the pattern of projections and functional subsystems is unknown.

\section{Discussion}

\section{Technical considerations}

The results can be best interpreted if we assume that only nerve terminals accumulate significant amounts of $\mathrm{D}^{-}{ }^{-} \mathrm{H}-\mathrm{Asp}$, and the labeling of somata is a result of retrograde axonal transport. This is indeed the only explanation for results obtained in previous studies where the injection site and the retrogradely labeled cells were in different areas of the brain connected by fiber pathways that are longer than the diffusion path of the amino acid (for review, see Cuenod et al., 1982; Cuenod and Streit, 1983; Ottersen and Storm-Mathisen, 1984b). However, in our study it might be argued that the labeled cells indicate the region throughout which the labeled amino acid is present shortly after its injection, and that uptake takes place at any site on the surface of the neurons. This is implausible, given that distinct patterns of labeling depended on which lamina was injected. For example, injections in layer III gave a much wider lateral labeling in layer $\mathrm{V}$ than injection in layer IVC, which is much closer to $\mathrm{V}$; or injections of layer I led to a wide lateral labeling in layer IVB, but this was not observed when the injection moved into layer III and therefore even closer to IV. Although uptake by dendrites and somata cannot be excluded, the labeling patterns strongly support the view that only terminal uptake can result in autoradiographically detectable labeling of somata.

The labeling of neuropil within layers that contain high density of labeled somata can be explained by the presence of label in the dendrites and local nerve terminals of these neurons. Anterograde transport of $\mathrm{D}^{-3} \mathrm{H}$-Asp may also contribute to neu- 
ropil labeling. However, it is unlikely that detectable labeling of cells can occur by transneuronal transport. First, the time from injection to fixation never exceeded $70 \mathrm{~min}$, second, the cell bodies that we interpreted as being retrogradely labeled were always more strongly labeled than the surrounding neuropil.

Labeling by fibers of passage can also be excluded. All projection neurons, including pyramidal cells, send their main axons through the gray matter in a strictly radial fashion. These radial fiber bundles were frequently passed by the capillary track, but there were no more labeled neurons in the line of the radial fibers towards the pia from the injection track than immediately lateral to it. Indeed, in many cases, for example, after layer IVB injections, there were hardly any labeled neurons towards the pia from the injection site, despite the track passing through the descending axons of layer II/III pyramidal cells. Since it seems that uptake occurs mainly at nerve terminals, the method is highly suitable for providing information on terminal fields and can be used to trace local circuits. A similar conclusion was reached in the spinal cord by observations of the selective labeling of somata following local injections (Rustioni and Cuenod, 1982). However, there are indications that only some of the putative excitatory amino acid connections can be revealed.

Negative results can arise for several reasons. Some classes of neurons that usc amino acids as transmitters may not have the uptake system in their terminals and may not become labeled. An example is the cerebellar Purkinje cell whose neurotransmitter is thought to be GABA but which could not be labeled by injecting ${ }^{3} \mathrm{H}-\mathrm{GABA}$ into either the terminal fields (see Cuenod et al., 1982) or the dendritic field (Hökfelt and Ljungdahl, 1972; Schon and Iversen, 1972). Failure to label neurons can also occur if the cells have only a small minority of their terminals in the injected area. Assuming an equal retrograde transport of transmitters and their metabolites from all the terminals of a neuron, the total somatic content represents at any one time the sum of transmitter arriving from all the terminals. Thus, to detect a soma as labeled, a significant proportion of its terminals should deliver labeled rather than unlabeled amino acid.

The examples described above indicate that lack of labeling alone gives little information on the chemical nature or projections of a particular cell population. It is noteworthy that the large neurons situated in layers IVB and in V/VI, which, from their known extracortical projections, are suspected of using excitatory amino acid transmitters, were not labeled in the present study. It is likely that the local collaterals of the large cells are more wide ranging, making it difficult to include a substantial population within any one injection.

A particular cortical layer often contained retrogradely labeled cells spread laterally to different distances after injections in different layers. It is not possible to decide whether the same lamina contained several populations of neurons labeled separately from different injection sites or whether the same neuron may have had axons in several laminae.

One major piece of information obtained with the method is an estimate of the lateral spread of the projections. It has to be remembered that the distance of even the most laterally located labeled cells may underestimate the length of lateral connections. First, as discussed above, a significant proportion of terminals has to be in the region of high concentration of labeled amino acid; therefore, the distalmost branches will often not provide enough label. Second, the lateral distance of retrogradely labeled cells from the radial line of the track may only be half of the spread of their axons since a cell may have an equally large projection in the opposite direction. However, the projections may often be asymmetrical in the tangential direction. It was frequently observed that both the labeled area represented by the neuropil and the area represented by the labeled somata were skewed towards one direction from the injection track; thus, the putative excitatory connections may be organized in an anisotropic fashion. This is in agreement with the observed patchiness of retrograde and anterograde HRP labeling in previous studies of the cortex of primates (Goldman and Nauta, 1977; Wong-Riley, 1979; Rockland and Lund, 1983; Livingstone and Hubel, 1984a, b; Schwartz and Goldman-Rakic, 1984).

\section{Immunocytochemical evidence for selectivity of uptake}

The main support for the selectivity of $\mathrm{D}^{-}{ }^{3} \mathrm{H}-\mathrm{Asp}$ labeling of neurons that presumably use excitatory amino acids as transmitters comes from the results of biochemical and pharmacological studies on the same pathways and from the lack of labeling of pathways that use GABA or an amine as transmitter (Streit, 1980). The present study provides further support for the selectivity by demonstrating that neurons that contain $\mathrm{GABA}$, which comprise about $20 \%$ of all neurons in striate cortex (Hendry et al., 1987), are not labeled by $\mathrm{D}^{-}{ }^{3} \mathrm{H}$-Asp cven if it was delivered in their axonal fields. The same neurons are readily labeled when ${ }^{3} \mathrm{H}-\mathrm{GABA}$ is injected at the same sites (Kisvarday et al., 1986a). The only exceptions are the neurons in layer I, most of which contain GABA (Gabbott and Somogyi, 1986; Hendry et al., 1987), as well as accumulate GABA (Somogyi et al., 1983). We have no convincing explanation of this difference. Since the dura was removed from above the injection site, cells in layer I were exposed to unusual physiological conditions, and this may have evoked the accumulation of the amino acid.

\section{Comparison of retrograde labeling by $D^{-3} H-A s p$ or by ${ }^{3} H-G A B A$}

Several of the labeling patterns obtained in the present study resembled those obtained by injections of ${ }^{3} \mathrm{H}-\mathrm{GABA}$. In particular, the projection from layer IVC/V to layer III, including the wider lateral extent of the cells of origin in layer $\mathrm{V}$; the layer IVC projection to layers V/VI; the layer VI projection to layer IV; and the layer II/upper III projection to layer VI had similarities, as shown by the 2 different amino acids (Somogyi et al., 1981a, 1983). This similarity is partly a consequence of the partial nonselectivity of the ${ }^{3} \mathrm{H}-\mathrm{GABA}$ labeling. Recently, we found that a substantial proportion of cells that accumulate ${ }^{3} \mathrm{H}$ GABA in the monkey's striate cortex were not immunoreactive for GABA, and this was particularly so in layers IVC and V. The partial nonselectivity of ${ }^{3} \mathrm{H}-\mathrm{GABA}$ labeling necessitates that the labeled neurons are also examined by GABA immunocytochemistry, if the pattern of GABAergic projections is of interest. Thus, it was shown that despite the contamination of the ${ }^{3} \mathrm{H}$-GABA-labeled sample by GABA-immunonegative cells, a large number of neurons with distinct interlaminar projections contained endogenous GABA (Kisvarday et al., 1986a).

The present study proved that the $\mathrm{D}^{3} \mathrm{H}$-Asp-labeled neurons form a distinct population, immunonegative for GABA except in layer I. Therefore, it is concluded that in some intracortical circuits putative excitatory connections, visualized here with $\mathrm{D}-{ }^{3} \mathrm{H}-\mathrm{Asp}$ labeling, and putative inhibitory connections, revealed earlier by combined ${ }^{3} \mathrm{H}-\mathrm{GABA}$ labeling and GABA immunocytochemistry (Kisvarday et al., 1986a), are organized in 
parallel, originating from the same layer and providing terminals in the same target layer. Lund (1987) reached the same conclusion by examining the axonal patterns of Golgi-impregnated neurons and inferring their transmitter characteristics.

\section{Cell type of $D^{-3} H-A s p$-accumulating neurons}

In axonal transport studies with $\mathrm{D}^{-} \mathrm{H}$-Asp and involving the corticocortical (Fisher et al., 1982; Manzoni et al., 1986; Barbaresi et al., 1987), corticostriatal (Streit, 1980), corticothalamic (Baughman and Gilbert, 1981; Rustioni et al., 1983), corticocollicular (Baughman and Gilbert, 1981; Matute and Streit, 1985), and corticocuneate (Rustioni and Cuenod, 1982) pathways, the pyramidal shape of the labeled cells and the morphology of the cortical efferent neurons known from HRP studies left little doubt that the amino acid was selectively accumulated by pyramidal cells. Some of the neurons that accumulated $\mathrm{D}^{-}{ }^{3} \mathrm{H}-\mathrm{Asp}$ in a previous study in the squirrel monkey (Caroll and Wong-Riley, 1985), as well as in the present study, were pyramidal shaped with a prominent labeled apical dendrite. In a preliminary study, Contamina et al. (1984) reported the labeling of Golgi-impregnated pyramidal cells by intracortical $\mathrm{D}^{3} \mathrm{H}$-Asp injection. We attempted to identify the intracortically labeled cells by Golgi impregnation, but this was unsuccessful because of the poor quality of the impregnation obtained in those particular animals.

However, since GABA-positive cells, which have smooth dendrites (Houser et al., 1984), were not labeled in the present study, the pyramidal cclls and the spiny stellate cells of layer IV remain the only candidates to account for the large number of $\mathrm{D}^{-3} \mathrm{H}$-Asp-accumulating neurons. This is supported by the good agreement between some of the intracortical pathways revealed here and the axonal arborizations of neurons revealed by single-cell staining methods (Ramon y Cajal, 1899, 1911; Valverde, 1971; Lund, 1973, 1984; Szentagothai, 1973, 1975; Lund and Boothe, 1975).

Putative excitatory pathways as revealed by $D^{-}{ }^{3} H-A s p$ transport: Comparison with connections revealed by other methods

Previous studies on the intracortical connectivity of striate cortex in monkeys employed electrophysiological methods (Mitzdorf and Singer, 1978), single-cell staining (Valverde, 1971; Lund, 1973, 1987; Lund and Boothe, 1975), and population staining (Rockland and Lund, 1983; Blasdel et al., 1985; Fitzpatrick et al., 1985). The transport of $\mathrm{D}^{-3} \mathrm{H}-\mathrm{Asp}$ substantially extends the available information and suggests that some of the pathways proposed earlier use excitatory amino acids as transmitters.

The most detailed studies of the intrinsic axonal patterns in the primate striate cortex have been carried out using extracellular HRP injections (Blasdel et al., 1985; Fitzpatrick et al., 1985). HRP is taken up not only by terminals but also by fibers of passage, and the injections would have labeled not only putative excitatory cells but also the GABAergic neurons and probably also some extrinsic afferents. Nevertheless, careful analysis of the axonal and retrograde labeling, the way HRP was delivered, and comparison with single neuron data allowed Fitzpatrick et al. (1985) and Blasdel et al. (1985) to provide a detailed picture of interlaminar and lateral projections. Our results are in good agreement with their conclusions, indicating that the bulk of the labeling obtained with HRP corresponds to projections made by putative excitatory neurons. However, there are some differences, and additional pathways arc revcalcd by $\mathrm{D}-{ }^{3} \mathrm{H}-$ Asp uptake.

Iateral projections. The widespread projections from layers IVB and V to layer I have not, to our knowledge, been reported earlier. Thus, the cells and dendrites entering layer I can have long lateral cxcitatory input from at least 2 sources. Because of their GABA content the effect of laterally projecting cells in layer I remains to be established. It is noteworthy that neurons in layers IVB and $\mathrm{V}$ have similar long lateral projections within their own layers, revealed here as well as by HRP transport (Rockland and Lund, 1983; Blasdel et al., 1984). The projections to layer I are not reciprocated, and there is little projection from layer IVB to layer $V$ that can be labeled by $\mathrm{D}^{-}{ }^{3} \mathrm{H}$-Asp. Thus, layer $\mathrm{V}$ cells are largely independent of the other two lateral systems. At the same time layer V seems to project to layer IVB since we consistently found labeled neurons in upper layer $\mathrm{V}$ following injections into IVB.

The somewhat less extensive lateral system involving neurons of upper layer VI seems to be independent of the system in layer V. These cells spread their terminals in lower layer VI and contribute few if any terminals to the other layers above.

There was less lateral labeling in layers II/III than expected on the basis of HRP studies (Rockland and Lund, 1983; Blasdel et al., 1985), either with injections of layers II/III or with injections of layer V. Similarly, in the squirrel monkey only sparse perikaryal labeling was observed in layers II/III following injections of $\mathrm{D}^{-3} \mathrm{H}-\mathrm{Asp}$ (Carroll and Wong-Riley, 1985). Since a few labeled cells were present radially to the injection site, the sparse lateral labeling is probably due to low terminal density and not to the lack of the uptake system in the supragranular pyramidal cells.

Input to layers $I I-I I I$. The transport of $\mathrm{D}^{-3} \mathrm{H}-\mathrm{Asp}$ consistently showed more widespread projections from layer $\mathrm{V}$ to the whole depth of layers I-III than did the transport of HRP (Fitzpatrick et al., 1985), and this pathway is very extensive in terms of the number of neurons involved. Small pyramidal cells in layer $\mathrm{V}$ are known to have recurrent axons to the supragranular layers (Ramon y Cajal, 1911; Valverde, 1971, 1986; Lund, 1973; Szentagothai, 1973; Lund and Boothe, 1975), but the extent of these projections to over a millimeter is only apparent in the $\mathrm{D}^{3} \mathrm{H}_{-}$ Asp preparations. Layer $\mathrm{V}$ is therefore a major source of excitatory input to the supragranular layers. A similar conclusion was reached on the basis of single-cell staining in the cat's striate cortex (Martin and Whitteridge, 1984).

The projection from layer IVB to layers II/III involved few small cells and was much smaller than reported in HRP experiments by Blasdel et al. (1985), who described a strong focused projection radial to the injection track. Technical factors can account for the difference. The HRP labeling could result from the labeling of axons passing through the injection sites, and it is possible that $\mathrm{D}^{-}{ }^{3} \mathrm{H}$-Asp is not taken up by the cells providing this pathway. Similarly, we have found little evidence with our method for a layer II/III projection to layer IVB, which was described using HRP transport by Blasdel et al. (1985) in the macaque monkey and which was proposed also in the squirrel monkey (Fitzpatrick et al., 1983).

The input from layer IVC to layers II/III found here with $\mathrm{D}^{-}{ }^{3} \mathrm{H}-\mathrm{Asp}$ is in good agreement with that demonstrated by HRP in the macaque (Fitzpatrick et al., 1985) but is in contrast to results in the squirrel monkey, in which layer IVC was thought not to project to upper layer III (Fitzpatrick et al., 1983). The transport of $\mathrm{D}^{-3} \mathrm{H}-\mathrm{Asp}$ confirmed that the cells in the upper two 
thirds of the beta sublayer and the lower half of the alpha sublayer are the main sources for the projection. Although there was a tendency to label more cells in IVC-beta after lower layer III injections, we could not see the clear separation of input to layers IIIA and IIIB described by Fitzpatrick et al. (1985). The continuity of labeled cells in IVC-alpha and =beta projecting to layer III is interesting because the 2 classes of geniculate afferents are well segregated at the alpha/beta border. The overlap in the lamina IV output of these magno- and parvocellular systems may be only apparent since the axons of alpha and beta cells could contact separate cell populations in layers II/III. There is now strong support for the lateral segregation of physiologically different neurons in layers II/III, as well as for their separate termination in prestriate area V2 (Livingstone and Hubel, 1984a).

Fitzpatrick et al. (1985) discovered that the bottom of layer IVC-beta contained cells with extremely focused projection to the III/IVA border. This pathway has been confirmed with $\mathrm{D}^{-}{ }^{3} \mathrm{H}-$ Asp transport. Since no GABA-postive cell was labeled, it is now apparent that, in addition to the smooth dendritic cells known to have axons with this projection (Lund, 1987), putative excitatory cells also contribute to this restricted projection. This is a good example for anatomically parallel pathways provided by matching putative excitatory and inhibitory neurons. Spiny stellate cells have been shown to have axons that correspond to this excitatory pathway (Lund and Boothe, 1975; Valverde, 1981, 1986).

Layer VI also has a projection to layer II/III, which is restricted in its lateral extent, and is a general feature of all cortical areas (Divac et al., 1987). This pathway probably involves different cells from those projecting to layer IV.

Inputs to layer $I V$. The common prominent feature of layer IVB-C is the strong interconnection of cells within each sublamina, which is very localized in IVC-beta but wide ranging in IVC-alpha and IVB. Single-cell studies indeed show that the spiny stellate cells that are responsible for the $\mathrm{D}-{ }^{3} \mathrm{H}-\mathrm{Asp}$ uptake have extensive local collaterals within their own layer (for review, see Lund, 1984), and electron microscopic evidence suggests that they mainly connect to spines of other spiny stellate cells (Saint Marie and Peters, 1985; Kisvarday et al., 1986b). Thus, within the thalamorecipient layer IVC, the interconnections among neurons using excitatory amino acids can contribute to the overall excitation provided by geniculate input.

A similar positive feedback could be provided by the strong layer VI input to layer IV, which is consistently labeled by $\mathrm{D}^{-}{ }^{3} \mathrm{H}-$ Asp in the monkey and originates from corticogeniculate pyramidal cells that have been labeled by $D^{-}{ }^{3} \mathrm{H}-\mathrm{Asp}$ from the thalamus in the cat (Baughman and Gilbert, 1981). However, in the cat it was proposed that these axon collaterals terminate mainly on inhibitory neurons (McGuire et al., 1984), and that through their activation layer VI input could provide the structural basis for the elaboration of end-inhibition (Bolz and Gilbert, 1986). The presence of a strong layer VI input to layer IVC in the monkey, where the receptive fields are circular and have center/surround organization, suggests that in the monkey this pathway is unlikely to deal with the end-inhibitory property of elongated receptive fields.

Another, though smaller, $\mathrm{D}^{-}{ }^{3} \mathrm{H}$-Asp-accumulating input comes to layer IV from upper layer V. This circuit was also noted by Fitzpatrick et al. (1985), though they left the possible termination open because of the uncertainties of the HRP method.

Inputs to layer $V$. With our method this layer could not be subdivided into an upper and a lower sublayer in terms of its inputs. In tcrms of its outputs, the subdivision is probably valid for certain pathways, but in several cases, such as the projection to layers I-III, the entire depth of layer V seems to contribute to the projection. This raises the general question of how the laminae can be subdivided. The results of this study suggest that layers, as well as sublayers, can only be divided for some circuits and these divisions should not be treated rigidly and generalized to all pathways that involve the layer.

Apart from strong interconnections within layer V, layers III and VI provide its major excitatory inputs. Both were also seen in HRP studies (Rockland and Lund, 1983, Fitzpatrick et al., 1985), but the layer VI input could not be attributed to nerve terminals because HRP may have been taken up by apical dendrites. Layer $\mathrm{V}$ also receives excitatory input directly from layer IVC and an input from scattered cells situated in layer IVB. These inputs have been described from HRP transport by Fitzpatrick et al. (1985), and Golgi-impregnated spiny stellate cells have been seen to send axons into layer V (Valverde, 1971; Lund, 1973). The transport of $\mathrm{D}^{3} \mathrm{H}-\mathrm{Asp}$ did not show differences in the contribution of the IVC-beta and -alpha sublayers, as described from HRP studies (Blasdel et al., 1985; Fitzpatrick et al., 1985).

Inputs to layer VI. Electrophysiological evidence shows that many neurons in layer VI receive monosynaptic geniculate input (Mitzdorf and Singer, 1978; Bullier and Henry, 1980). The geniculate axons, especially in the monkey, provide very few boutons to layer VI (Blasdel and Lund, 1983) compared with the input to layer IVC. Consequently, in order to achieve activation of cells the input is probably concentrated onto a subpopulation of the neurons, most likely corticogeniculate cells. Thus, it is not surprising that other putative excitatory inputs converge onto layer VI, among them one from layer IVC also described in HRP studies (Fitzpatrick et al., 1985). The scant input from layer IVB is similar to the one to layer V. Layer VI, as in other species, probably contains several systems (Lund and Boothe, 1975; Valverde, 1986; Katz, 1987), and this is reflected in its inputs; for example, the layer $\mathrm{V}$ input is mainly concentrated in the upper half of layer VI, while an input from layer II is concentrated in the lowermost part of the layer. The latter pathway has not becn describcd carlicr. It is very focused, with small lateral extent, and is rather different from the layer III projection to the infragranular layers, which arises from cells located more diffusely. Its functional significance is unknown.

\section{Comparison of excitatory links revealed by current source density analysis or transport of $D^{-3} \mathrm{H}-\mathrm{Asp}$}

Milzdorf and Singer (1979), using current source density analysis, showed the excitatory nature of several of the pathways revealed in the present study. In particular, the connections within IVC-alpha and -beta, from IVC-alpha to IVB and III, from IVC-beta to layer III, including a prominent projection to the IVA/III border, are in good agreement. Following electrical stimulation, a prominent polysynaptic activity was also revealed in layer $\mathrm{V}$ that may have corresponded to the projection of layer II/III and/or layer IV to V.

However, several of the pathways revealed with $\mathrm{D}^{-3} \mathrm{H}-\mathrm{Asp}$ were not detected. The most extensive of these is the layer $\mathrm{V}$ projection to supragranular layers. The functional significance of this circuit remains to be established. It has been suggested that it may only provide background modulatory influence over the main pathways originating from IVC (Blasdel et al., 1985), but it is equally feasible that the IVC and $\mathrm{V}$ inputs do not 
terminate on the same cells in layer III but belong to separate systems.

\section{Conclusion}

The selective uptake and transport of $\mathrm{D}^{-3} \mathrm{H}$-Asp used to visualize putative excitatory pathways and similarly the transport of ${ }^{3} \mathrm{H}$ GABA coupled with immunocytochemistry for the tracing of putative inhibitory pathways, have revealed several new intracortical projections in the primate striate cortex. The comparison of pathways revealed by $\mathrm{D}^{-3} \mathrm{H}$-Asp with known or suspected GABAergic pathways in many cases' suggests a parallel organization of putative excitatory and inhibitory intrinsic connections, as also noted in Golgi studies (Lund, 1987). It might be profitable to extend the work to other, functionally distinct cortical fields to reveal the characteristics of local excitatory and inhibitory connections required for the specific tasks of different cortical areas.

\section{References}

Aoki, E., R. Semba, K. Kato, and S. Kashiwamata (1987) Purification of specific antibody against aspartate and immunocytochemical localization of aspartergic neurons in the rat brain. Neuroscience 21 : 755-765.

Barbaresi P., M. Fabri, F. Conti, and T. Manzoni (1987) $\mathrm{D}-[3 \mathrm{H}]$ aspartate retrograde labelling of callosal and association neurones of somatosensory areas I and II of cats. J. Comp. Neurol. 263. $159-178$

Baughman, R. W., and C. D. Gilbert (1981) Aspartate and glutamate as possible neurotransmitters in the visual cortex. J. Neurosci. 1:427439.

Berl, S., and D. D. Clarke (1983) The metabolic compartmentation concept. In Glutamine, Glutamate, and GABA in the Central Nervous System, L. Hertz, E. Kvamme, E. G. McGeer, and A. Schousboe, eds., pp. 205-217, Liss, New York.

Blasdel, G. G., and D. Fitzpatrick (1984) Physiological organization of layer 4 in macaque striate cortex. J. Neurosci. 4: 880-895.

Blasdel, G. G., and J. S. Lund (1983) Termination of afferent axons in macaque striate cortex. J. Neurosci. 3: 1389-1413.

Blasdel, G. G., J. S. Lund, and D. Fitzpatrick (1985) Intrinsic connections of macaque striate cortex: Axonal projections of cells outside lamina 4C. J. Neurosci. 5: 3350-3369.

Bolz, J., and C. D. Gilbert (1986) Generation of end-inhibition in the visual cortex via interlaminar connections. Nature 320:362-365.

Bullier, J., and G. H. Henry (1980) Ordinal position and afferent input of neurons in monkey striate cortex. J. Comp. Neurol. 193: 913-935.

Campistron, G., R. M. Buijs, and M. Geffard (1986) Specific antibodies against aspartate and their immunocytochemical application in the rat brain. Brain Res. 365: 179-184.

Carroll, E. W., and M. Wong-Riley (1985) Correlation between cytochrome oxidase staining and the uptake and laminar distribution of tritiated aspartate, glutamate, $\gamma$-aminobulyrate and glycine in the striate cortex of the squirrel monkey. Neuroscience 15:959-976.

Christie, M. J., R. J. Summers, J. A. Stephenson, C. J. Cook, and P. M. Beart (1987) Excitatory amino acid projections to the nucleus accumbens septi in the rat: A retrograde transport study utilizing $\mathrm{D}\left[{ }^{3} \mathrm{H}\right]$ aspartate and $\left[{ }^{3} \mathrm{H}\right] \mathrm{GABA}$. Neuroscience $22: 425-439$.

Contamina, P., L. Martinez-Millan, M. J. Pinilla, and J. L. Pena (1984) Morphologically identified neurons which uptake $3 \mathrm{H}$-aspartate and 3H-glutamate in the rabbit's visual cortex. Trab. Inst. Cajal 85: 101.

Conti, F., A. Rustioni, P. Petrusz, and A. C. Towle (1987) Glutamatepositive neurons in the somatic sensory cortex of rats and monkeys. J. Neurosci. 7: 1887-1901.

Cuenod M., and P. Streit (1983) Neuronal tracing using retrograde migration of labeled transmitter-related compounds. In Methods in Chemical Neuroanatomy, A. Bjorklund and T. IIokfelt, eds., pp. 365397, Elsevier, Amsterdam.

Cuenod, M., P. Bagnoli, A. Beaudet, A. Rustioni, L. Wiklund, and P. Streit (1982) Transmitter-specific retrograde labelling of neurons. In Cytochemical Methods in Neuroanatomy, V. Chan-Palay and S. L. Palay, eds., pp. 17-44, Liss, New York.
Curtis, D. R., A. W. Duggan, D. Felix, G. A. R. Johnston, A. K. Tebecis, and J. C. Watkins (1972) Excitation of mammalian central neurones by acidic amino acids. Brain Res. 41: 283-301.

Divac, I., S. Marinkovic, J. Mogensen, W. Schwerdtfeger, and J. Regidor (1987) Vertical ascending connections in the isocortex. Anat. Embryol. 175: 443-455.

Dow, B. M. (1974) Functional classes of cells and their laminar distribution in monkey visual cortex. J. Neurophysiol. 37: 927-946.

Fisher, B. O., O. P. Ottersen, and J. Storm-Mathisen (1982) Axonal transport of D- $[3 \mathrm{H}]$-aspartate in the claustrocortical projection. Neuroscience 7: $\mathrm{S} 69$.

Fitzpatrick, D., K. Itoh, and I. T. Diamond (1983) The laminar organization of the lateral geniculate body and the striate cortex in the squirrel monkey (Saimiri sciureus). J. Neurosci. 3: 673-702.

Fitzpatrick, D., J. S. Lund, and G. G. Blasdel (1985) Intrinsic connections of macaque striate cortex: Afferent and efferent connection of lamina 4C. J. Neurosci. 5: 3329-3349.

Fonnum, F. (1984) Glutamate: A neurotransmitter in mammalian brain. J. Neurochem. 42: 1-11.

Gabbott, P. L. A., and P. Somogyi (1986) Quantitative distribution of GABA-immunoreactive neurons in the visual cortex (area 17) of the cat. Exp. Brain Res. 61: 323-331.

Gilbert, C. D., and T. N. Wiesel (1983) Clustered intrinsic connections in cat visual cortex. J. Neurosci. 3: 1116-1133.

Goldman, P. S., and W. J. H. Nauta (1977) Columnar distribution of cortico-cortical fibers in the frontal association, limbic, and motor cortex of the developing Rhesus monkey. Brain Res. 122: 393-413.

Hendrickson, A. E. (1985) Dots, stripes and columns in monkey visual corlex. Trends Neurosci. 8: 406-410.

Hendrickson, A. E., J. R. Wilson, and M. P. Ogren (1978) The neuroanatomical organization of pathways between the dorsal lateral geniculate nucleus and visual cortex in old world and new world primates. J. Comp. Neurol. 182: 123-136.

Hendry, S. H. C., H. D. Schwark, E. G. Jones, and J. Yan (1987) Numbers and proportions of GABA-immunoreactive neurons in different areas of monkey cerebral cortex. J. Neurosci. 7: 1503-1519.

Hicks, T. P., and R. C. A. Guedes (1983) Neuropharmacological properties of electrophysiologically identified, visually responsive neurones of the posterior lateral suprasylvian area. A microiontophoretic study. Exp. Brain Res. 49: 157-173.

Hicks, T. P., W. D. Ruwe, W. L. Veale, and J. Veenhuizen (1985) Aspartate and glutamate as synaptic transmitters of parallel visual cortical pathways. Exp. Brain Res. 58: 421-425.

Hökfelt, T., and A. Ljungdahl (1972) Autoradiographic identification of cerebral and cerebellar cortical neurons accumulating labeled gamma-aminobutyric acid ([3H]GABA). Exp. Brain Res. 14: 354-362.

Houser, C. R., J. E. Vaughn, S. H. C. Hendry, E. G. Jones, and A. Peters (1984) GABA neurons in the cerebral cortex. In Cerebral Cortex. Functional Properties of Cortical Cells, E. G. Jones and A. Peters, eds., pp. 63-89, Plenum, New York.

Hubel, D. H., and T. N. Wiesel (1968) Receptive fields and functional architecture of monkey striate cortex. J. Physiol. (Lond.) 195: 215243.

Hubel, D. H., and T. N. Wiesel (1972) Laminar and columnar distribution of geniculo-cortical fibers in the macaque monkey. J. Comp. Neurol. 146: 421-450.

Hubel, D. H., and T. N. Wiesel (1977) Functional architecture of macaque monkey visual cortex. Proc. R. Soc. London [Biol.] 198: $1-59$.

Katz, L. C. (1987) Local circuitry of identified projection neurons in cat visual cortex brain slices. J. Neurosci. 7: 1223-1249.

Kisvarday, Z. F., A. Cowey, A. D. Smith, A. J. Hodgson, and P. Somogyi (1984) Relationship between GABA immunoreactive neurons and neurons accumulating [3H]GABA or [3H]-D-aspartate in striate cortex of monkey. Trab. Inst. Cajal 85: S55.

Kisvarday, Z. F., A. Cowey, A. J. Hodgson, and P. Somogyi (1986a) The relationship between GABA immunoreactivity and labelling by local uptake of [3H]GABA in the striate cortex of monkey. Exp. Brain Res. 62: 89-98.

Kisvarday, Z. F., A. Cowey, and P. Somogyi (1986b) Synaptic relationships of a type of GABA-immunoreactive ncuron (clutch ccll), spiny stellate cells and lateral geniculate nucleus afferents in layer IVC of the monkey striate cortex. Neuroscience 19:741-761.

Krnjevic, K., and J. W. Phillis (1963) Iontophoretic studies of neurons in the mammalian cerebral cortex. J. Physiol. (Lond.) 165: 274-304. Livingstone, M. S., and D. H. Hubel (1984a) Anatomy and physiology 
of a colour system in the primate visual cortex. J. Neurosci. 4: 309356.

Livingstone, M. S., and D. H. Hubel (1984b) Spccificity of intrinsic connections in primate primary visual cortex. J. Neurosci. 4: 28302835 .

Lorente de No, R. (1949) Cercbral cortex: Architecture, intracortical connections, motor projections. In Physiology of the Nervous System, J. H. Fulton, ed., pp. 288-312, Oxford U. P., New York.

Lund, J. S. (1973) Organisation of neurons in the visual cortex, area 17, of the monkey (Macaca mulatta). J. Comp. Neurol. 147: 455496.

Lund, J. S. (1984) Spiny stellate neurons. In Cerebral Cortex, A. Peters and E. G. Jones, eds., pp. 255-308, Plenum, New York.

Lund, J. S. (1987) Local circuit neurons of macaque monkey striate cortex: I. Neurons of laminae $4 \mathrm{C}$ and 5A. J. Comp. Neurol. 257: 6092.

Lund, J. S., and R. Boothe (1975) Interlaminar connections and pyramidal neuron organization in the visual cortex, area 17 , of the macaque monkey. J. Comp. Neurol. 159: 305-334.

Madl, J. E., A. J. Beitz, R. L. Johnson, and A. A. Larson (1987) Monoclonal antibodies specific for fixative-modified aspartate: Immunocytochemical localization in the rat CNS. J. Neurosci. 7:2639 2650.

Manzoni, T., P. Barbaresi, and M. Fabri (1986) D-[3H]aspartate retrograde labelling of association neurones in area SI of the cat. Neurosci. Lett. 67: 175-180.

Martin, K. A. C., and D. Whitteridge (1984) Form, function, and intracortical projections of spiny neurones in the striate visual cortex of the cat. J. Physiol. (Lond.) 353: 463-504.

Matute, C., and P. Streit (1985) Selective retrograde labelling with $\mathrm{D}-\left[{ }^{3} \mathrm{H}\right]$-aspartate in afferents to the mammalian superior colliculus. J. Comp. Neurol. 241: 34-49.

McGuire, B. A., J.-P. Hornung, C. D. Gilbert, and T. N. Wiesel (1984) Patterns of synaptic input to layer 4 of cat striate cortex. J. Neurosci. 4: 3021-3033.

Mitzdorf, U., and W. Singer (1978) Prominent excitatory pathways in the cat visual cortex (A17 and A18): A current source density analysis of electrically evoked potentials. Exp. Brain Res. 33: 371394.

Nicklas, W. J. (1986) Glia-neuronal interrelationships in the metabolism of excitatory amino acids. In Excitatory Amino Acids, P. J. Roberts, J. Storm-Mathisen, and H. F. Bradford, eds., pp. 57-66, Macmillan, Basingstoke, UK.

Ottersen, O. P., and J. Storm-Mathisen (1984a) Glutamate- and GABAcontaining neurons in the mouse and rat brain, as demonstrated with a new immunocytochemical technique. J. Comp. Neurol. 229: 374392.

Ottersen, O. P., and J. Storm-Mathisen (1984b) Neurons containing or accumulating transmitter amino acids. In Classical Transmitters and Transmitter Receptors in the CNS, Part 2, A. Bjorklund, T. Hökfelt, and M. J. Kuhar, eds., pp. 141-246, Elsevier, Amsterdam.

Ottersen, O. P., and J. Storm-Mathisen (1985) Different neuronal localization of aspartate-like and glutamate-like immunoreactivities in the hippocampus of rat, guinea-pig and Senegalese baboon (Papio papio), with a note on the distribution of $\gamma$-aminobutyrate. Neuroscience 16:589-606.

Ramon y Cajal, S. (1899) Estudios sobre la corteza cerebral humana. Corteza visual. Rev. Trim. Microgr. 4: 1-63.

Ramon y Cajal, S. (1911) Histologie du systeme nerveux de l'homme et des vertebres. In II Maloine, Paris.

Rockland, K. S., and J. S. Lund (1983) Intrinsic laminar lattice connections in primate visual cortex. J. Comp. Neurol. 216: 303-318.

Rustioni, A., and M. Cuenod (1982) Selective retrograde transport of D-aspartate in spinal interneurons and cortical neurons of rats. Brain Res. 236: 145-155.
Rustioni, A., D. E. Schmechel, R. Spreafico, S. Cheema, and M. Cuenod (1983) Excitatory and inhibitory amino acid putative neurotransmitters in the ventralis posterior complex. An autoradiographic and immunocytochemical study in rats and cats. In Somatosensory Integration in the Thalarnus, G. Macchi, A. Rustioni, and R. Spreafico, cds., pp. 365-383, Elscvicr, Amsterdam.

Saint Marie, R. L., and A. Peters (1985) The morphology and synaptic connections of spiny stellate neurons in monkey visual cortex (area I\%): A Golgi-electron microscopic study. J. Comp. Neurol. 233: 213235.

Schon, F., and L. L. Iversen (1972) Selective accumulation of [3H]GABA by stellate cells in rat cerebellar cortex in vivo. Brain Res. 42: 503-507.

Schwartz, M. L., and P. S. Goldman-Rakic (1984) Callosal and intrahemispheric connectivity of the prefrontal association cortex in Rhesus monkey: Relation between intraparietal and principal sulcal cortex. J. Comp. Neurol. 226: 403-420.

Somogyi, P., A. Cowey, N. Halasz, and T. F. Freund (1981a) Vertical organization of neurons accumulating $3 \mathrm{H}-\mathrm{GABA}$ in the visual cortex of the Rhesus monkey. Nature 294: 761-763.

Somogyi, P., T. F. Freund, N. Halasz, and Z. F. Kisvarday (1981b) Selectivity of neuronal $3 \mathrm{H}-$ GABA accumulation in the visual cortex as revealed by Golgi staining of the labelled neurons. Brain Res. 225: $431-436$.

Somogyi, P., A. Cowey, Z. F. Kisvarday, T. F. Freund, and J. Szentagothai (1983) Retrograde transport of 3H-GABA reveals specific interlaminar connections in the striate cortex of monkey. Proc. Natl. Acad. Sci. USA 80: 2385-2389.

Somogyi, P., A. J. Hodgson, I. W. Chubb, B. Penke, and A. Erdei (1985) Antiserum to $\gamma$-aminobutyric acid. II. Immunocytochemical application to the central nervous system. J. Histochem. Cytochem. 33: 240-248.

Sternberger, L. A., P. H. Hardy, Jr., J. J. Cuculis, and H. G. Meyer (1970) The unlabelled antibody enzyme method of immunohistochemistry. Preparation and properties of soluble antigen-antibody complex (horseradish peroxidase-antihorseradish peroxidase) and its use in identification of spirochetes. J. Histochem. Cytochem. 18:315333.

Storm-Mathisen, J., A. K. Leknes, A. T. Bore, J. L. Vaaland, P. Edminson, F-M.S. Haug, and O. P. Ottersen (1983) First visualization of glutamate and GABA in neurones by immunocytochemistry. Nature 301: 517-520.

Streit, P. (1980) Selective retrograde labeling indicating the transmitter of neuronal pathways. J. Comp. Neurol. 191: 429-463.

Streit, P. (1984) Glutamate and aspartate as transmitter candidates for systems of the cerebral cortex. In Cerebral Cortex, E. G. Jones and A. Peters, eds., pp. 119-145, Plenum, New York.

Szentagothai, J. (1973) Synaptology of the visual cortex. In Handbook of Sensory Physiology, R. Jung, H. Autrum, W. R. Loewenstein, D. M. McKay, and H. L. Tenber, eds., pp. 269-324, Springer-Verlag, Berlin.

Szentagothai, J. (1975) The 'module-concept' in cerebral cortex architecture. Brain Res. 95: 475-496.

Tsumoto, T., H. Masui, and H. Sato (1986) Excitatory amino acid transmitters in neuronal circuits of the cat visual cortex. J. Neurophysiol. 55: 469-483.

Valverde, F. (1971) Short axon neuronal subsystems in the visual cortex of the monkey. Intern. J. Neurosci. 1 : 181-197.

Valverde, F. (1986) Commentary: Intrinsic neocortical organization: Some comparative aspects. Neuroscience 18: 1-23.

Wong-Riley, M. (1979) Columnar cortico-cortical interconnections within the visual system of the squirrel and Macaque monkeys. Brain Res. 162: 201-217. 